\title{
Changing Current Appraisals of Mothers Leads to Changes in Childhood Memories of Love towards Mothers
}

\author{
Lawrence Patihis ${ }^{1}$, Cristobal S. Cruz, \& Mario E. Herrera \\ Department of Psychology, University of Southern Mississippi
}

${ }^{1}$ To whom correspondence should be addressed: L.Patihis@usm.edu

\begin{abstract}
False memories in therapy have previously been identified as problematic, but memory of emotion distortions have been underdiscussed in this context. Past research has suggested that cognitive reappraisals are associated with changes in memory of emotions. We investigated whether these findings would generalize to an important emotion (love), target (mothers), and time (childhood). In samples of adults, we manipulated current appraisals of mothers to examine the effect on memory of love felt in childhood towards mothers. In Experiment 1, we found significant differences between appraisal conditions on memory of love-effects that persisted for four weeks. In Experiment 2, the effect of reappraisal on memory of love replicated with a pretest-posttest experiment. Pretest current feelings of love were biased when recalled after the experiment. Reevaluating parents in therapy, or elsewhere, may result in memory distortion of important aspects of autobiographical memory.
\end{abstract}

Keywords: Memory, Emotion, Love, Appraisal, Mother, Autobiographical memory

Past research on false memories has provided valuable cautionary information for clinicians who practice psychotherapy. Much research has shown memory in general is reconstructed (Bartlett, 1932; for a review, see Loftus, 2005). Research demonstrated that childhood events that did not happen could be implanted as memories using suggestive post event information, repetition, and/or guided imagery techniques (e.g., Hyman, Husband, \& Billings, 1995; Loftus \& Pickrell, 1995; Patihis \& Loftus, 2016; Porter, Yuille, \& Lehman, 1999; Shaw \& Porter, 2015). This research helped inform many clinicians of how to avoid false memories in therapy. Nevertheless, there is a subtler type of memory distortion that is lesser known-the distortion of memory of emotions. Past research has suggested that memory of emotions can change as current cognitions change (Levine, 1997; for a review, see Levine, Lench, \& Safer, 2009). As a memory trace of an emotion fades over time, a person relies upon current cognitive appraisals of the past situation when reconstructing their memory of how they felt. Other research has suggested that not only are memories of basic emotions malleable, but so too are memories of complex emotions and sensations (e.g., memory of grief, Safer, Bonanno, \& Field, 2001; memory of pain, Smith \& Safer, 1993). It is unclear whether such past findings would generalize to the therapy-relevant scenario in which changes in current cognitive appraisals of parents would lead to changes in remembering important complex emotions that we would presumably not want to change, such as love. It is also unclear whether such past research would generalize to memories of emotions during $t$ important developmental periods such as childhood. In addition, although the causal mechanism has been hypothesized to be changing current cognitive appraisals (e.g., Levine, 1997; Levine et al, 2009), this has not been fully supported by a sufficient number of experiments. In the two current experiments, we explored whether childhood memory of love towards one's mother is malleable.

\section{Past Research on the Reconstructive Nature of Memory}

Our research is informed by the general theory that memory is reconstructed from a combination of memory traces and current cognitions (e.g., Bartlett, 1932; Katz, 1989; Loftus, 2005; Ross, 1989; Wilson \& Ross, 2003). A number of memory distortion paradigms are well established (Loftus, Miller, \& Burns, 1978; Roediger \& McDermott, 1995; Crombag, Wagenaar, \& van Koppen, 1996; Garry, Manning, Loftus, \& Sherman, 1996). The most relevant research to our current study, though, is the recent research into the malleability of memory for emotions that has begun to solidify into a new 
paradigm (for a review, see Levine et al., 2009). Evidence suggests that memory of emotions (and sensations) may be malleable according to current appraisals of an event - whether the target of the remembered emotion is towards an event connected to a political event (Levine, 1997), a legal verdict (Levine, Prohaska, Burgess, Rice, \& Laulhere, 2001), an exam (Safer, Levine, \& Drapalski, 2002), physical pain (Hovasapian \& Levine, 2016), or the death of a spouse (Safer, Bonanno, \& Field, 2001).

\section{Theory}

The overall theory to emerge from such research is that changes in current appraisals of the most important goal-relevant aspects of a past situation, can bias the recall of emotions related to that situation (Levine, 1997). This theory contrasts with some earlier theories that emotions are indelible (LeDoux, 1992), from which we might predict memory for emotions would be relatively stable and accurate. Levine (1997) built on cognitive appraisal theories of emotions (e.g., Arnold, 1960; Lazarus, 1991; Schachter \& Singer, 1962; Scherer, Schorr, \& Johnstone, 2001)—which posits that cognitive appraisals lead to current emotions - and extended this theory to propose that changes in appraisals may lead to changes in memory for emotion. Figure 1 illustrates a simplification of this basic theoretical model. The fundamentals of this model states that current appraisals of the environment (including appraisals of agents, such as people) in relation to the self's important goals, cause current emotions (solid arrow in Figure 1). For example, if you appraise that a person is blocking you from reaching an important goal, you will feel anger towards that person. If you reappraise the situation and come to understand the person is not deliberately obstructing you, the emotion will change. In the lower part of the model in Figure 1, changing cognitive appraisals partially cause changes in memories of emotions (the thinner dotted line signifies a relatively partial cause in a multi-causal system). Not shown in Figure 1, there are also non-biasing factors that affect memories of emotions, such as accurate memory traces of the emotion or accurate memory of the situation.

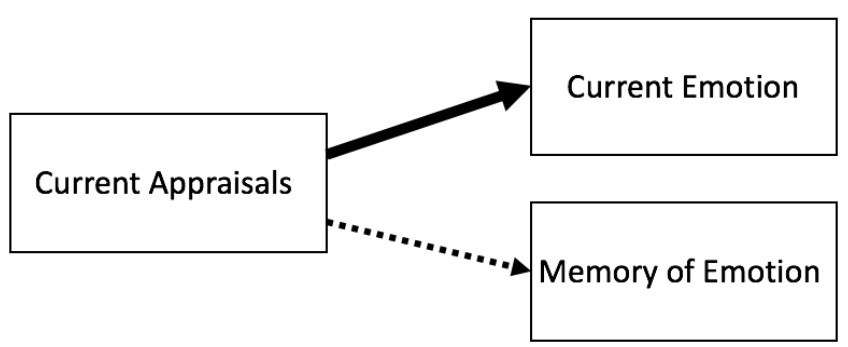

Figure 1. Basic theoretical framework where current cognitive appraisals of a situation is a cause of current emotions, and this is illustrated by the top solid arrow and captures the core essence of the cognitive appraisal theory of emotions (Arnold, 1960; Lazarus, 1991; Schachter \& Singer, 1962). The thinner broken bottom arrow illustrated the suggestion that current cognitive appraisals of a situation are a partial cause memory of emotion and current emotion (Levine, 1997).

This theory should also extend to the relationship between the current cognitive appraisals of a person and to memories of emotion towards that person (rather than appraisals and memories of an event). Because a person has agency in an environment to facilitate or block important goals, and this can be perceived to be related to their attributes, then changes in appraisals of their goal-relevant attributes (such as the tendency to facilitate goals via attributes such as generosity, supportiveness, etc.) may lead to changes in memory of emotions towards that person.

\section{Longitudinal Research on the Malleability of Emotions}

Some longitudinal research demonstrates the instability of memory of emotions. First, we will examine one study in detail to clarify to the reader what we mean by changing appraisals and the malleability of memory of emotion. Levine (1997) found that supporters of the U.S. presidential candidate Ross Perot tended to bias their memories of emotion about his withdrawal from the race in accordance with changes in their appraisal of his withdrawal. The participants rated their current emotions towards Perot a few days after his withdrawal from the 1992 presidential race. Perot re-entered the race a few months later, in October. After the election in November (in which Perot came third but captured $19 \%$ of the vote) Levine asked the participants what they remembered of their emotions when Perot had originally withdrawn 
from the race. Some supporters stayed loyal, others did not, and these differences provided naturally occurring changes in appraisal of the target person. She found that their memories of their emotions were biased in accordance with how they had reappraised Perot after his withdrawal. For example, if Perot had lost some participants' support after his decision to withdraw, and they still held a diminished appraisal of him after the election, they would remember their initial anger somewhat accurately. In contrast, those supporters who had turned against Perot after his withdrawal, but subsequently reappraised him positively and returned as supporters remembered being less angry about his withdrawal than they actually were. These returning supporters also overestimated their reports of feeling hope after his withdrawal, again fitting with the theory that changing appraisals drove that bias.

Other longitudinal work has suggested a relationship between reappraisals and changes in memory of emotion (Levine et al., 2001; Levine, Whalen, Henker, \& Jamner, 2005; Safer, Bonanno, $\&$ Field, 2001). Levine et al. (2001) examined the emotions undergraduates felt about the O.J.

Simpson not guilty verdict one week after the verdict. Participants were later asked to remember those emotions two months and one year later. Their appraisals of whether they believed Simpson was guilty or not was also measured over time. They found that changes over time in memory for happiness, anger, and surprise were found in directions consistent with current appraisals of the not guilty verdict. In other work, Levine et al. (2005) examined the relationship between appraisals of the terrorist attacks on September 11, 2001, and memories of emotions three and eight months after the attacks. In a sample of adolescents and parents, those who appraised the attacks as having less impact recalled lower negative emotions after $9 / 11$, and in these participants negative emotions decreased with time. In contrast, those who appraised the attack as having higher impact showed an increase over time of memory of negative emotions. Examining a different scenario, Safer et al. (2001) asked adults to report their feelings of grief six months after the death of their spouse, and then to recall those feelings of grief 4.5 years later. After several years, those whose grief did not diminish much (compared to others whose grief diminished more) tended to overestimate how much grief they had felt initially. We might speculate that variation in reappraising the loss in a negative or positive direction led to inconsistencies in some of their memories of grief. These longitudinal studies relied upon naturally occurring changes in appraisals that were not randomly assigned, which raises doubts over whether there is a causal relationship between changing cognitive appraisals and memory of emotion. There have been relatively few experimental designs that examine this possible causal relationship.

\section{Experimental Research on the Malleability of Memory of Emotion}

Only a limited number of studies have involved experimental manipulation of current appraisals with memory of emotion as the outcome measure (e.g., Keuler \& Safer, 1998; Safer, Levine, \& Drapalski, 2002; Hovasapian \& Levine, 2016). In what they called "the first controlled experiment to investigate memory of emotions," Keuler and Safer (1998; p. S128) found that in graduate students, randomly assigning one group to receive feedback about passing a comprehensive exam (all passed so it was all positive feedback) biased their memories of pre-exam anxiety in the upward direction, compared to those that received no feedback. While it is unclear why those receiving positive feedback over-estimated memory of anxiety, the study did establish that post event information about the past event can affect memory of anxiety. Some studies were unable to randomly assign the direction of the appraisal manipulation, in part due to attempts to maintain high ecological validity. For example, in Safer et al. (2002) the type of feedback (positive or negative) subjects received depended upon the participants test performance in a college midterm exam. Safer et al. (2002) asked undergraduates before an exam to report their anxiety about the exam, and found that after the exam those receiving positive feedback (that they got a good grade) about their grade underestimated pre-exam anxiety. Those receiving negative feedback overestimated their pre-exam anxiety. Importantly, those randomly assigned to receive no feedback were less biased in their recall of pre-exam anxiety. This research was promising, but the type of feedback the participants received was dependent on their own performance in the exam. In a different type of experimental approach, Hovasapian and Levine (2016) randomly assigned participants into groups that varied on how a painful experience (putting an arm in ice water) 
was appraised. The researchers did not find a main effect for appraisal group on memory of pain, but did find an interaction. There was only a difference between an appraisal-up condition and a control condition on memory of pain within those scoring high on anxiety sensitivity.

Earlier experiments examined the independent variable of current sensations of pain (rather than current appraisals), and investigated the effect on memory of pain. For example, Smith and Safer (1993) randomly assigned chronic pain patients into a group that received physical therapy (which reduced their current pain) or into a control group. The found that those in the physical therapy group felt lower current pain and underestimated how much pain they had felt before physical therapy. Smith et al. (1998) found similar patterns in an experiment with cancer patients and the use of physical therapy to reduce current pain. These experiments suggest that the malleability of emotions may extend to other emotion-like experiences, such as memory of sensations. It makes sense that the remembrance of pain might utilize current appraisals of the situation, and that those appraisals might be more positive if pain is presently lower.

In summary, experimental and longitudinal research has suggested a possible causal relationship between changing appraisals and changing memory of emotions. Past research articles on this topic are still limited in number, and there is a need for more experimental research, as well as exploration of whether the effects generalize to different situations that have not yet been studied.

\section{The Present Experiments}

The Gap in the Literature. No previous

research to our knowledge has extended the malleability of memory for emotion research into the domain of parents, nor into the time period of childhood. To our knowledge, no past research has examined the malleability of the memory of love, towards any target person (for discussion of love treated as an emotion see Shaver, Morgan, \& Wu, 1996; Campos, Shiota, Keltner, Gonzaga, \& Goetz, 2013). In addition, the experimental research on memories of emotion in the past has not yet fully established a causal relationship between current cognitive appraisals and memories of emotion.

The Basics in Brief: The Proposed IV, DV, and Other Measures. In the current experiments, we utilize between-subjects experiments. Our independent variable is current appraisals of the mother on attributes that are goal relevant to the participant (e.g., the participant's appraisal of their mother's current warmth, generosity, etc.). This independent variable is manipulated by writing prompts attempting to raise or lower current cognitive appraisals of mothers on attributes related to the goals of offspring. The dependent measure is the participant's memory of love they felt (consisting of questions on strength and frequency) towards their mother during transitional years in childhood. This measure is divided into 3 subscales: memory of love felt during first, sixth, and ninth grade (equivalent to ages 6-7, 11-12, and 14-15 years old) in order to achieve a detailed picture of the memory from early to later childhood. These are the years in which many children transition schools, and thus we thought these would be meaningful and somewhat remembered years. A secondary dependent measure of interest are current feelings of love.

Why We Chose the Dependent Variable.

We argue that our memories during childhood of past felt love and affection towards our parents are a particularly important part of our life narrative. This likely is true whether that narrative is positive or negative. We speculate that to those that remember feeling love towards parents in childhood, such memories are meaningful aspects of their lives. To others, the memory of a lack of love may be a meaningful, though negative, part of their autobiographical story. How we remember our past emotions towards parents could affect our relationship with them. For those who cherish their memories of love they felt in childhood, they might hope that such memories are indelible. They would not want them to change, and if they do change they would like to understand how they change. For these reasons, for our first exploration of the malleability of childhood emotions, we chose to focus our efforts on the memory of love, and to measure love as if it were an emotion. In the current experiments, we specifically examine memories felt towards mothers, rather than emotions toward an event, because asking about memories of emotion towards a person is novel, and we consider the target person particularly important. It also is a concern that reappraisals in therapy might change memory of important emotions towards parents, as well as change current emotions. We chose to ask participants to remember the love they felt during 
periods of whole years in childhood, because we considered such a measure more stable and representative of what the person remembers feeling at that age (compared to the feelings of love they felt at a specific event). Although feelings of love and emotions at specific episodic events are a direction for future research, we first wanted to investigate this broader assessment of love in childhood which we consider a meaningful approximation of remembered love in general.

\section{Cognitive Appraisals in the Context of}

Our Study. In this article, current appraisal of a parents means how we evaluate a parent on attributes that are potentially goal-related and thus may elicit emotion in offspring. Specifically, a parent's tendency to be generous, warm, supportive, able to give and receive love, and to give good guidance are all attributes that may be perceived to help facilitate goals of the offspring. These attributes of parents relate to offspring's needs for support and information, which in turn relate to life goals to survive, thrive, learn, and belong.

Appraisals of agents (people, in this case) who help or hinder our important goals will be emotion eliciting, according to cognitive appraisal theory of emotion (see Lazarus, 1991). Such goal-relevant appraisals may also affect memory of emotions, according to adaptations of that theory (see Levine, 1997; Levine et al., 2009). We may change our current appraisals of parents during any number of events or experiences in life (e.g., psychotherapy, self-help books, parental divorce, leaving home, having children of our own, observing parents interact with grandchildren, observing parents change with age, learning about the content of a will, etc.). If we assess our parents as having these positive goal-related attributes, these will elicit positive emotions, including, we predict, feelings of love. In addition, we predict changing appraisals may lead to changes in memories of love towards parents. As our memories of the love we felt towards a person inevitable fade with time, when we are asked to recall memories of love we once felt we may reconstruct the memories using current appraisals of the target person to help us do so.

In our study, we use random assignment into conditions that are either designed to increase current cognitive appraisals of the participants mother (Mother Appraisal Up condition), to decrease it (Mother Appraisal Down condition), or to serve as control conditions. Based on past research and our arguments outlined above, we propose the following hypotheses and research questions:

Hypothesis 1. Our independent variable manipulation (i.e., writing prompts) should significantly change current appraisals of attributes relevant to parenting in the target parent. This is a manipulation check: a test of whether the attempted manipulation of the IV does indeed shift the IV. Specifically, we expect Mother Appraisal Down condition to elicit the lowest current appraisals of mothers, and the Appraisal Up condition to elicit the highest. We expect the control conditions to have intermediate scores on current appraisals of mothers.

Hypothesis 2. Applying cognitive appraisal theory to memories of emotion, we predict that as memories of emotions fade with time, they become vulnerable to distortion according to current appraisals. Therefore, we predict that if current appraisals go up, the memories of love towards mothers will also go up. Specifically, we assess subjective self-reported memories of love towards their mother during first, sixth, and ninth grade. If current appraisals are significantly lower, due to our manipulation, in the Appraisal Down condition, compared to the Appraisal Up condition, we predict that memory of love will correspondingly be significantly lower in the Appraisal Down condition.

Hypothesis 3. From a direct application of the cognitive appraisal theory of emotion, reappraisals of one's mother on attributes that are important to parenting (e.g., supportiveness or generosity) should change current feelings of love towards the mother. If current appraisals go up, subjective self-reported current feelings of love should go up, and if appraisals go down, current feelings of love should go down. Assuming the IV manipulations do shift the IV as predicted (Hypothesis 1), we predict the Appraisal Up condition will elicit significantly higher scores on current feelings of love, compared to the Appraisal Down condition.

Hypothesis 4. Attempting to change current appraisals of mothers may inadvertently change current mood. It has previously been suggested that current appraisals may be a larger predictor, compare to current mood, of memory of emotion (e.g., Levine, 1997, wrote: "Current appraisals of the emotion-eliciting event should be more 
predictive of memory biases than a person's mood at the time of recall," p. 168).We therefore predict that current appraisals of mothers will be a stronger predictor of changes in memory of love, compared to changes in mood.

Hypothesis 5. We investigate whether any changes in memory of love endure over time. Such changes in memories may endure because the act of remembering love in childhood may cause a consolidation of that memory, causing it to endure; or because the initial reappraisals of current appraisals endure for a time, and the corresponding changes in memory of love also endure until the reappraisals return to baseline. This is assessed at two and four weeks in Experiment 1, and at eight weeks after the manipulation in Experiment 2.

\section{Experiment 1}

Pilot studies in the Supplemental Materials informed the development of the experimental manipulations in Experiment 1. In a number of additional pilot experiments cumulating in Pilot Study 2, we designed, modified, and identified writing prompt manipulations that reliably changed current appraisals of mothers in samples from Amazon Mechanical Turk (AMT; Buhrmester, Kwang, \& Gosling, 2011). In pilot testing, we also attempted to use vignettes - paragraphs of relevant text to attempt to change appraisals, but those manipulations failed to affect the independent variable. Because in the pilot studies we had found that the condition Mother Appraisal Down was the most effective in changing current appraisals, we introduced a control group called Teacher Appraisal Down to Experiment 1-which contained the same writing prompts, but with the word "mother" replaced with "teacher." This allowed us to test whether writing positively about someone else caused changes in appraisals towards mothers or whether writing about someone specifically changed appraisals and memory of love (the latter being what we would predict). We also included a Null control condition in which participants received no writing prompts and instead proceeded to the next part of the study. In this first experiment we utilized these current appraisal-changing prompts to investigate the effect on memory of love.

\section{Participants}

\section{Method}

Participants were recruited from a new AMT sample $(N=301$; all studies in our research program excluded all previous participants throughout) of mean age $36.2(S D=11.1$; range 18 68 ), with $76.1 \%$ (229) female, $23.3 \%$ (70) male, and $.7 \%$ (2) choosing "other (please specify)." Ethnicity was self-reported as: $6.6 \%$ (20) Hispanic or Latino, with $91.7 \%$ (276) not Hispanic or Latino. Race was distributed as: $75.4 \%$ (227) White, $13.6 \%$ (41) Black or African American, 9.3\% (28) Asian, 3.0\% (9) American Indian or Alaska Native, 2.3\% (7) Native Hawaiian or Pacific Islander, and 2.7\% (7) chose other. Mean self-reported socioeconomic status (SES), on a scale from 1 to 10, was 4.97 (SD $=1.7)$. The sample size of 300 was chosen so that the size of the effect detectable was small ( $\mathrm{G}^{*}$ Power calculation with $r=.15 ; \alpha=.05$, Power $=.8,4$ group between factors, three repeated measures ANOVA; yields a Sample size suggestion of 324; Faul, Erdfelder, Lang, \& Buchner, 2007), and so that the sample size was not so small as to lead to Type I errors and exaggerated sample size estimates.

\section{Basic Design}

This experiment consisted of a betweensubjects experimental manipulation in Session 1 to assess the effect of current appraisals of memory of love towards the participant's mother. Follow ups in Session 2 (2 weeks later) and Session 3 (4 weeks later) assessed how long any effect lasted.

\section{Materials}

Appraisal Experimental Manipulations. Participants were randomly assigned to one of four groups. The four experimental conditions designed to change the independent variable (current appraisals), were a Mother Appraisal Down, Mother Appraisal Up, and two control comparison conditions: a Teacher Appraisal Down condition and a Null condition. These materials are given in Supplemental Material Appendix 1.

\section{Mother Appraisal Up condition.}

Participants in the Mother Up condition were required to write several sentences giving recent examples of when their mother had exhibited evidence of having a positive attribute. There were five such writing prompts. The following was an example writing prompt: "Please write 3-4 sentences giving the most recent examples of when your mother showed warmth towards you." This example was designed to prime an example of warmth to raise current appraisals of the mother currently being warm. Another example was: 
"Please write 3-4 sentences giving the most recent examples of when your mother showed competence (effectiveness) in her life." Other prompts asked for 2-3 sentences of recent examples of their mother showing generosity, good guidance towards the participant, and examples of when the mother gave and received love.

Mother Appraisal Down condition. In this condition, participants were given five prompts which were similar to the Mother Appraisal Up condition prompts, but adjusted with the words such as "lack of" added in to the prompts. For example, one writing prompt read: "Please write 3-4 sentences giving the most recent examples of when your mother showed a lack of warmth towards you." Another example was: "Please write 3-4 sentences giving the most recent examples of when your mother showed a lack of competence (effectiveness) in her life." Other writing prompts asked for recent examples of the mother showing a lack of generosity, giving bad guidance, and not giving love to the participant.

Teacher Appraisal Down condition. These writing prompts were identical to the Mother Appraisal Down condition, except the word "mother" was replaced by the word "teacher" throughout. Due to trying to keep the prompts appropriate, the words "not give love to you" from the Mother Appraisal Down condition were changed to "not give praise to you" in the teacher version of the prompts.

Null condition. Those in the control condition skipped the writing prompts and instead saw blank screen with an arrow at the bottom with instructions to proceed to the next page.

Current Appraisal of Mothers: Manipulation Check Questions. Participants were presented with five items that asked them to currently evaluate various attributes of their mother (see Appendix S2 for materials). Participants were first asked "How do you evaluate your mother currently on:" followed by the five items. Two example items were: "Current warmth of your mother" and "Current generosity of your mother." Beneath each item was a fully anchored Likert-type questions and for each evaluation participants were given the choices of $1=$ poor, $2=$ fair, $3=\operatorname{good}, 4$ $=$ very good, or $5=$ excellent as answers. An additional choice of N/A was given, which if chosen was set to give missing data. The mean of the items was used as our measurement for current mother appraisal. The five items yielded high internal reliability (e.g., Experiment 1, Time 1, Cronbach's $\alpha=.941)$.

\section{Memory of Love towards Parents} Questionnaire (MLPQ). The 10-item mother subscales for the MLPQ were presented to participants (see Appendix S3 for materials). The four subscales presented asked about the time periods first grade (ages 6-7), sixth grade (ages 1112), ninth grade (ages 14-15), and current feelings. This questionnaire consists of questions asking about both the frequency and strength of memories of past feelings of love (and synonyms of love, such as "affection", that are appropriate in the context of a parent-child relationship). An example of an item that measured memory of frequency of love was: "During the whole year when you were in first grade, how often on average did you feel love toward your mother?" For these frequency questions the Likert-like scale ranged from $0=$ Never to $6=$ All the time. An example of an item that measured memory of strength of love was: "During the whole year when you were in first grade, how strong on average was your love toward your mother?" For these strength questions, the Likert-like scale ranged from $0=$ Nonexistent to $6=$ Extremely Strong. Other words also used in the questionnaire in substitution for the word "love" were "affection", "warmth," "fondness," and "caring." In preliminary psychometric analyses, we found high internal reliability within subscales, that the subscales have factor loadings distinct from one another, and emerging evidence of discriminant and convergent validity (Patihis, Herrera, Huff, \& Arnau, in press; see also Patihis, Jackson, Diaz, Stepanova, \& Herrera, in press). In the current dataset we found, by design, very high internal validity within all four subscales (Experiment 1, Time 1: first grade: $\alpha=.981$; sixth grade: $\alpha=.983$; sixth grade: $\alpha=.987$; current: $\alpha=.990$ ).

\section{Positive and Negative Affect Schedule} (PANAS). We utilized the PANAS consisting of two 10 -item subscales representing negative and positive current affect/mood (Watson, Clark, \& Tellegen, 1988). In the current experiment, both subscales had high internal reliability (Experiment 1: time 1: positive affect $\alpha=.908$; negative affect $\alpha$ $=.938$ ) and the two subscales were negatively correlated with a small effect size, $r=-.112, p=$ .052 .

\section{Procedure}


Session 1: Experiment. The procedure for Session 1 involved first presenting demographic questions. Then, we randomly assigned participants into one of four writing-prompt conditions to manipulate current appraisals of the participant's mother (Appraisal Up, Appraisal Down; and two control groups: Null, Teacher Appraisal Down). For the wording of the questions and materials see Appendix S1. After this experimental assignment, all participants completed questions assessing current appraisal of their mothers (Appendix S2). Then participants completed the 10-item subscales of the Memory of Love towards Parents Questionnaire (Appendix S3), followed by the positive and negative affect scale (PANAS). After completing Session 1 participants were automatically given a secret code for payment of $\$ 1$ on AMT. Session 1 took approximately 19 minutes.

Session 2: First Follow Up. Two weeks later, the same participants were invited back, via email sent out by TurkPrime.com (Litman, Robinson, \& Abberbock, 2017). Session 2 contained the same materials as Session 1 except fewer demographic questions and no writing prompts (i.e. no experimental manipulation). Therefore, the participants received current appraisal questions followed by the MLPQ subscales, and the PANAS. After completing the session participants were automatically given a secret code for payment of $\$ .70$ on AMT. The session took approximately 11 minutes.

Session 3: Second Follow Up. Two weeks later (4 weeks after the initial experiment), participants were again invited back, and all participants received the same materials: demographic questions, Mother Appraisal Up writing prompts, the MLPQ subscales, and the PANAS. We put all participants through the Mother Appraisal Up condition for two reasons: (1) to see if it influenced the MLPQ scores, and (2) to ensure a positive end to the experiment for the participants. After completing the session participants read a debriefing sheet and were automatically given a secret code for a payment of $\$ 1.10$ on AMT. This session took approximately 19 minutes.

\section{Session 1: Experiment}

\section{Results and Discussion}

Hypothesis 1: Did the Manipulation Alter the IV (Appraisals)? In an ANOVA with current appraisals of mothers as the outcome variable, the
Mother Appraisal Down condition $(M=2.87, S D=$ $1.32)$, scored significantly lower on current appraisals of mother compared the Null $(M=3.67$, $S D=1.08, p<.001)$, Teacher Appraisal Down $(M=$ $3.77, S D=1.09 ; p<.001)$ and Mother Appraisal Up $(M=4.11, S D=0.96 ; p<.001)$ conditions. The Mother Appraisal Up condition scored significantly higher than the Null condition $(p=.018)$, and not significantly higher than the Teacher Appraisal Down condition $(p=.063)$. This effect of held when statistically adjusting for mood (see Supplemental Materials). The conditions succeeded in manipulating current appraisals (see Figure 2).
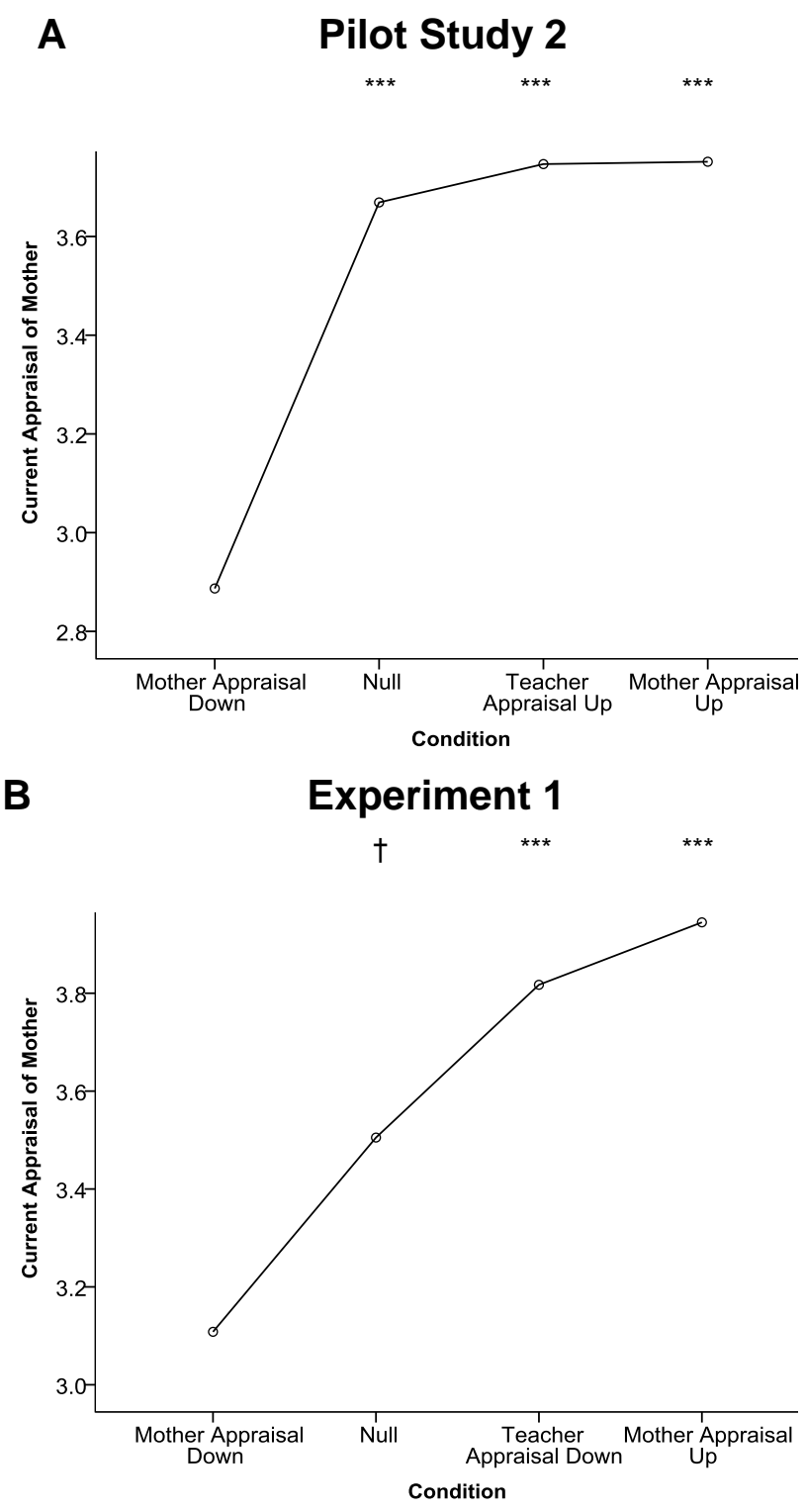

C Experiment 2 


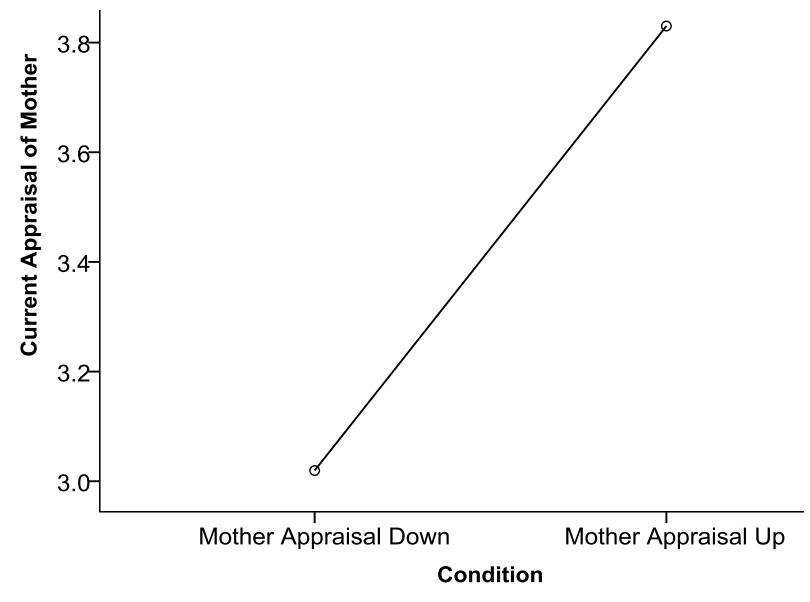

Figure 2: Manipulation checks for Pilot Study 2, Experiment 1, and Experiment 2. (A) There were significant differences between Mother Appraisal Up and Mother Appraisal Down conditions on current appraisals of mother's attributes important in parenting, in both pilot study $2(\mathrm{~A})$, Experiment 1 (B), and Experiment $2(\mathrm{C})$. Asterisks indicate that condition is significantly higher than the Mother Appraisal Down condition on that measure (LSD post hoc $p$-values): $\dagger=.054,{ }^{*} p<.05,{ }^{* *} p<.01{ }^{* * *} p$ $<.001$.

\section{Hypothesis 2: Did the Manipulation} Change Memories of Love? Table S1 in the Supplemental Material gives the descriptive and inferential statistics of the memory of love measures by Condition and by Time Period, as well as Cohen $d$ effect sizes for group comparisons. As illustrated further in Figure 3 (A, B, and C) there were significant differences between conditions on memory of love towards mothers during childhood. For all time periods (grades 1, 6, 9), the Mother
Appraisal Up condition had significantly higher memory of love scores (see Table S1 for descriptive statistics), compared to the Mother Appraisal Down condition (first grade $p=.003, d=.503$; sixth grade $p=.013, d=.413$; ninth grade: $p=.031, d=.362$ ). We note that the largest effect size of $d=.503$ was lower than the effect of those appraisal conditions on cognitive appraisal, $d=1.08$ ). These patterns of results indicate the experimental manipulation had a strong effect on current appraisals of mother (IV) and a statistically significant but weaker effect on memory of love towards mothers (DV).

Hypothesis 3: Did the Manipulation Change Current Feelings of Love? Table S1 also contains the descriptive and some inferential statistics for current feelings of love. As also shown in Figure 3 (graph D) Mother Appraisal Down condition $(M=3.96, S D=2.15)$, had significantly higher scores for current feelings of love towards mothers compared to the Mother Appraisal Up condition $(M=5.12, S D=1.15 ; p<.001 ; d=.675)$, and as compared to the two control conditions (see Table S1 for statistics). The finding that the appraisal up and down conditions had a stronger effect on current feelings of love $(d=.675)$, compared to memories of love ( $d=.503$ at most), is congruent with cognitive appraisal theory that states that current emotions are directly dependent on current appraisals, whereas memories of emotions are partially affected by appraisals (Figure 1). 

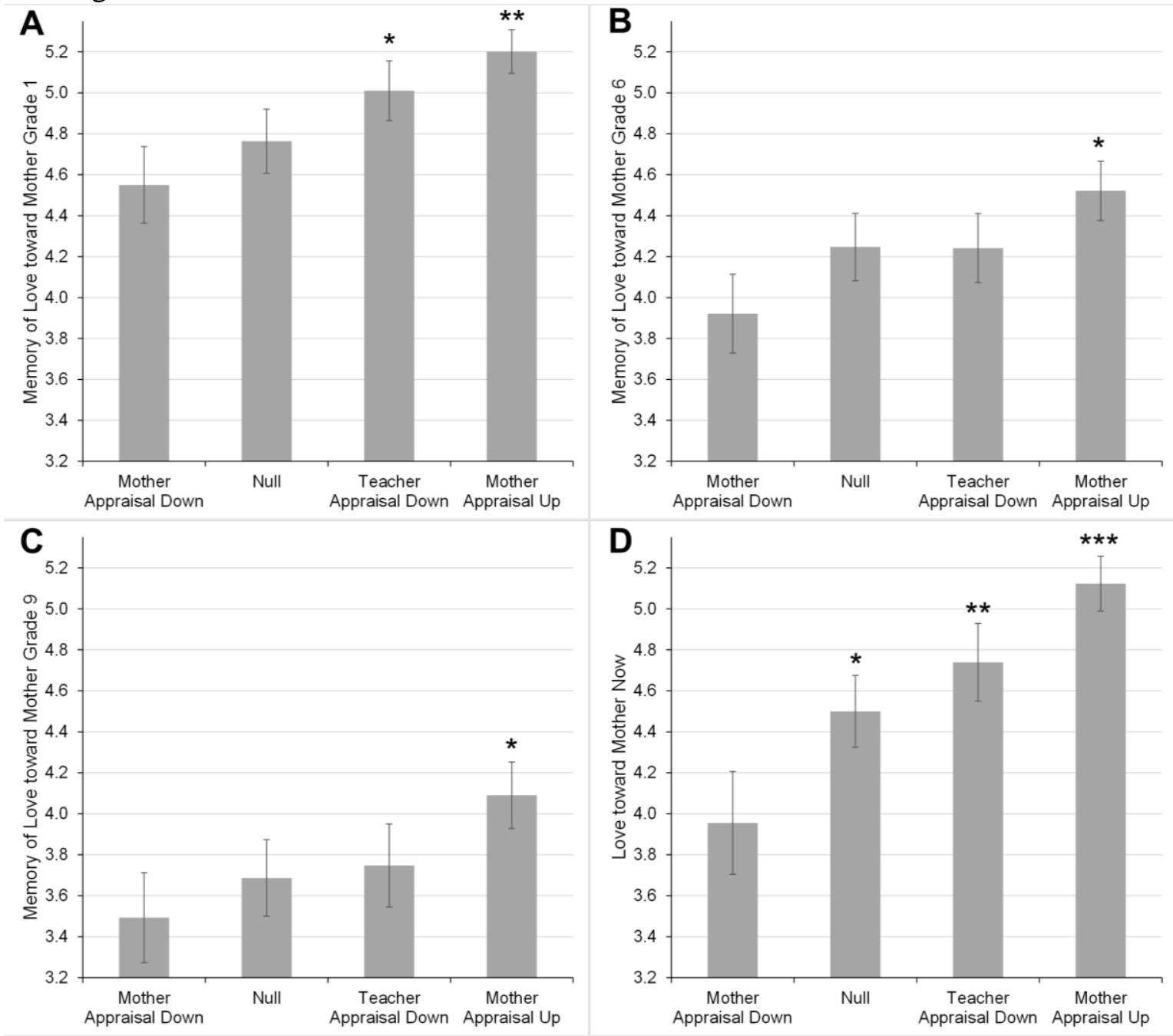

Figure 3. The effect of appraisal condition (x-axis) on memory of love towards mothers $(A, B, C)$ and on current feelings of love (D). Asterisks indicate that condition is significantly higher than the Mother Appraisal Down condition on that measure (LSD post hoc $p$ values): ${ }^{*} p<.05$ ${ }^{* *} p<.01{ }^{* * *} p<$ .001 . Error bars represent standard errors.

\section{Hypothesis 4: Statistically Adjusting for}

Mood. We investigated further to establish whether cognitive appraisals or current mood best explained these group differences. Using hierarchical linear regression, with the MLPQ Grade 1 composite score as the dependent measure, and Condition (dichotomized: Mother Appraisal Up, Mother Appraisal Down) as the independent variable, we found that current appraisal of mother was the covariate with the largest effect (partial correlation: $\left.r_{\mathrm{p}}=.479, p<.001\right)$, with current negative mood as a covariate of lesser effect size $\left(r_{\mathrm{p}}=-.166, p=.047\right)$, and current positive mood as a nonsignificant covariate $\left(r_{\mathrm{p}}=.105, p=.213\right)$. With the MLPQ Grade 6 subscale as the dependent measure, current appraisal again had the largest effect $\left(r_{\mathrm{p}}=.424, p<\right.$ $.001)$, followed by positive $\operatorname{mood}\left(r_{\mathrm{p}}=.228, p=\right.$ $.006)$, and negative mood ( $\left.r_{\mathrm{p}}=-.093, p=.267\right)$. Repeating this regression analysis with MLPQ Grade 9 as the outcome yielded similar results, though positive affect played was a larger predictor than before, but still less so than current appraisals (current appraisal, $r_{\mathrm{p}}=.400, p<.001$; positive affect, $r_{\mathrm{p}}=.334, p<.001 ;$ negative affect, $r_{\mathrm{p}}=$ $.075, p=.375)$. With current feelings of love as the dependent measure, current appraisal was the predictor with the largest effect size $\left(r_{\mathrm{p}}=.757, p<\right.$ $.001)$, followed by positive $\operatorname{mood}\left(r_{\mathrm{p}}=.141, p=\right.$ $.090)$, and negative mood ( $\left.r_{\mathrm{p}}=-.064, p=.447\right)$. An examination of collinearity revealed the Variance Inflation Factors (VIF) were less than 1.7 throughout. Current appraisal of mothers played a larger role than mood in every MLPQ subscale analysis. Mediation models using PROCESS macros (Hayes, 2012; 2013; Version 3.2 macro used in SPSS) found similar results - mood did not mediate the relationship between appraisal condition and memory of love or current feelings of love (see Supplemental Materials, p. S5).

Session 2 and 3: Two and Four Weeks Later 
Hypothesis 5: Did the Effects Endure? To investigate the duration of our experiment on memory of love, we invited all participants back two weeks (Session 2) and four weeks (Session 3) later for follow up assessments using the memory of love measure, and 203 participants completed all three sessions. In Session 2, participants received no manipulation, in Session 3 all participants completed the Mother Appraisal Up condition writing prompts (immediately before the memory of love questions) to end the experiment on a positive note.

The results on the MLPQ subscales are illustrated in Figure 4 over all three sessions, with appraisal condition shown on separate lines. As illustrated in Figure 4 (compare week 4 results), and as investigated in ANOVAs in the Supplemental Material (p. 5-6), the MLPQ subscales for current feelings of love and memory of first grade were particularly affected by appraisal condition, and the effect endured in those subscales into week 4 (differences between groups remained significant in subscales Grad 1 and Current). In contrast, for subscales for Grade 6 and 9, where episodic memory likely plays a larger competing role with current appraisals, the differences between conditions by the time of week 4 were statistically nonsignificant.
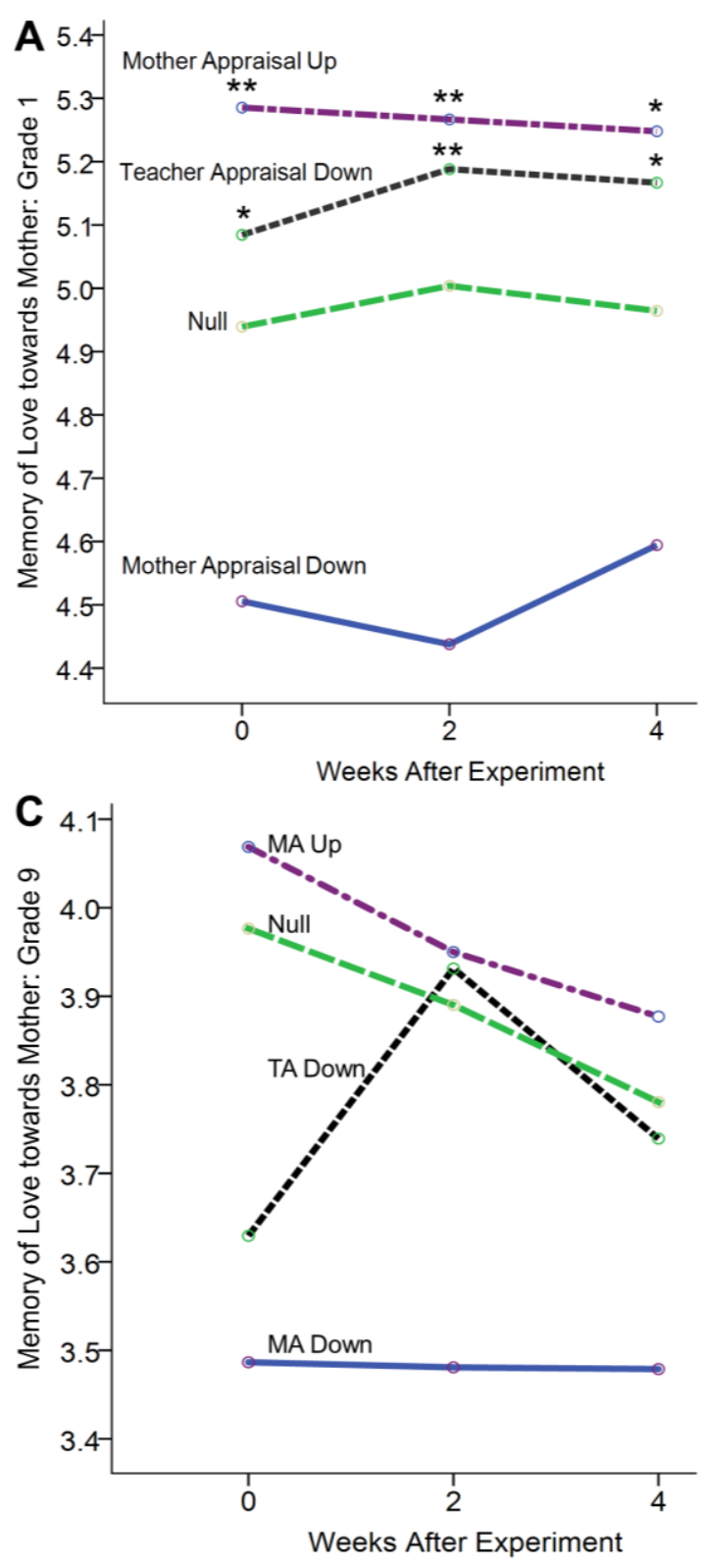
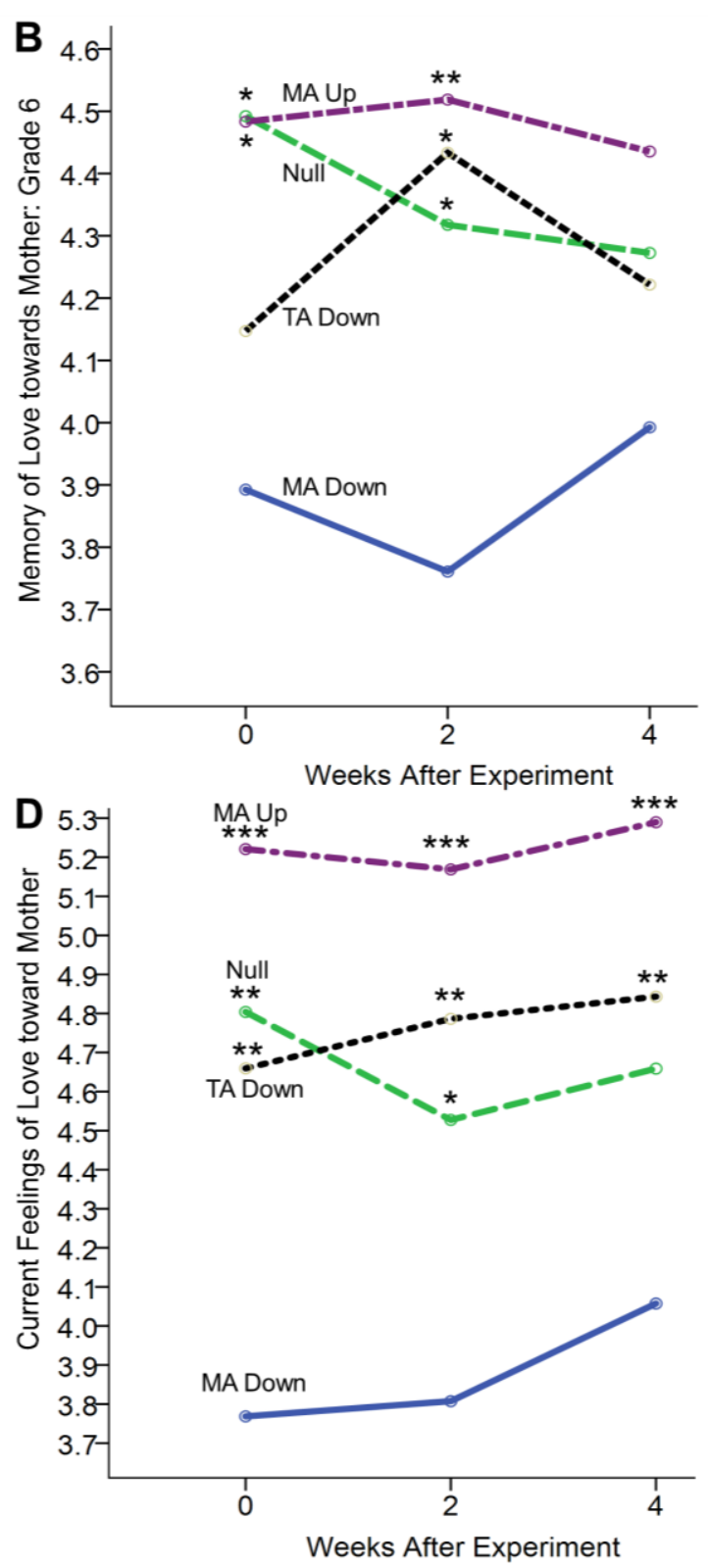

Figure 4. The effect of appraisal condition (separate lines) over three sessions $(x-$ axis) on memory of love towards mothers $(\mathrm{A}, \mathrm{B}, \mathrm{C})$ and on current feelings of love (D). MA = Mother Appraisal. TA = Teacher Appraisal. Asterisks indicate that condition is significantly higher than the Mother Appraisal Down condition at that particular time-point (ANOVA post hoc LSD $p$-values): * $p<$ $.05,{ }^{\star *} p<.01^{\star * *} p<$ .001 . 
In summary, it appears that our experiment manipulations may have affected memory of love and current feelings of love towards mothers. Nevertheless, because we did not take baseline measures of memory of love before the experiment, an alternative explanation could be that the Session 1 group differences were pre-existing and not caused by our appraisal manipulations. Though we considered this unlikely given our pilot studies found a similar effect of condition on appraisal, we cannot rule out this potential explanation. This led us to design a follow-up experiment utilizing a pretest-posttest design to further test the hypothesis that our appraisal conditions were causing changes in memory of love for mothers.

\section{Experiment 2}

In this experiment, we utilized a new AMT sample and collected pre-test measures on all four MLPQ subscales (this time using shorter 4-item subscales, see Appendix S3). Eight weeks later we invited those participants back for an experiment utilizing the two most effective conditions from the previous experiment: Mother Appraisal Up and Mother Appraisal Down. Eight weeks after the experiment, we again invited participants to participate again to assess the duration of the effect. In this experiment, we use a new design to retest Hypotheses 1 through 5.

\section{Participants}

Participants were from a new AMT sample $\left(N_{\text {pretest }}=302\right)$ of mean age $36.1(S D=11.1$; range 19-70), with $77.8 \%$ (235) female, $21.9 \%$ (66) male, and .3\% (1) specifying "nonbinary." Ethnicity was self-reported only in the second session $\left(N_{\text {experiment }}=\right.$ 202) as: $6.4 \%$ (13) Hispanic or Latino, with $93.6 \%$ (189) not Hispanic or Latino. Race was distributed as: $86.6 \%$ (175) White, 9.9\% (20) Black or African American, $4.5 \%$ (9) Asian, 2.0\% (4) American Indian or Alaska Native, and $1.5 \%$ (3) chose other. Mean self-reported socioeconomic status (SES), on a scale from 1 to 10 , was $5.09(S D=1.6)$. An initial sample of 300 was chosen because we expected attrition of participants from pretest to posttest, and we wanted to be sure we had as least as many participants per cell as in Experiment 1 (approximately 75 per cell), and we achieved this. For Session 2, 202 participants of those who had participated in Session 1 returned, and for Session 3, 206 participants returned (168 participated in all three sessions; 38 participants participated in Session 1 and 3 only).

\section{Materials}

Manipulation of Current Appraisals: Experimental Writing Prompts. The same writing prompts from Experiment 1 were used for the Mother Appraisal Up condition and the Mother Appraisal Down condition (for materials see Appendix S1). This manipulation in Experiment 2 was used at the beginning of the Session 2 only.

Manipulation Check: Current Appraisals of Mothers. The same five items used in Experiment 1 were used to assess the participants' current appraisal of their mother on goal-relevant attributes (materials in Appendix S2). The internal reliability of these current appraisal items was high $(\alpha=.921)$

MLPQ. A 4-item per subscale short form version of the MLPQ was used for Experiment 2. These four items are the first four shown in Appendix S3. These four items involved asking about the strength and frequency of feelings of love and affection. The intercorrelations between the 4items within each subscale indicated high internal reliability statistics within each subscale (Experiment 2, pretest: first grade, $\alpha=.959$; sixth grade, $\alpha=.962$; ninth grade, $\alpha=.967$; current, $\alpha=$ $.965)$.

PANAS. The PANAS was used as in Experiment 1. In the current experiment, both subscales had high internal reliability (Experiment 2: time 1: positive affect $\alpha=.914$; negative affect $\alpha$ $=.898$ ) and the two subscales were negatively correlated with a small effect size, $r=-.129, p=$ .025 .

\section{Procedure}

Session 1: Pretest. The procedure for Session 1 involved first presenting demographic questions. All participants completed questions assessing current appraisal of their mothers (Appendix S2). Then participants completed the 4item version subscales of the MLPQ (Appendix S3), and then the PANAS. After completing Session 1 participants were automatically given a secret code for payment of $\$ .50$ on AMT. Session 1 took approximately 12 minutes on average.

Session 2: Experiment. Eight weeks later the same participants were invited back, via emails sent out by TurkPrime.com, and 202 of the original 302 participated. Session 2 contained similar materials as Session 1 except after the demographic questions, participants were randomly assigning into one of two conditions: Mother Appraisal Up or 
Mother Appraisal Down (for materials see Appendix S1). After this experimental assignment, the participants received current appraisal questions, followed by the MLPQ subscales. An additional MLPQ subscale was added to ask, "Remember back to the day you completed Part 1 of this study," and an example of one of the 4 items in this subscale was "When you completed Part 1 of this study, how strong was your love toward your mother?"

Participants then completed the PANAS. After completing the session participants read a debriefing sheet and were automatically given a secret code for payment of $\$ 2$ on AMT. The session took approximately 22 minutes on average.

Session 3: Follow up. Eight weeks after the experiment (16 weeks after pretest), participants returned for a reassessment of the same measures reported in Session 1. There was no experimental manipulation or writing prompt in this session. This session took a mean of 10 minutes to complete.

\section{Results and Discussion Hypothesis 1: Did the Manipulation Alter the IV (Appraisals)?}

As in Experiment 1 and our pilot study, the appraisal condition writing prompts successfully changed appraisal of mother scores, a measure of the independent variable (see Figure 2,C). Eight weeks before the experiment, at pretest, the Mother Appraisal Up condition $(M=3.53, S D=1.15, n=$ 91) was not significantly different on current appraisals of mothers than the Mother Appraisal Down condition $(M=3.47, S D=1.23 . n=84)$, $t(173)=0.30, p=.766$, Cohen's $d=.050$. In contrast, after the experiment in Session 2, the Mother Appraisal Up condition scored significantly higher $(M=3.83, S D=1.12)$ on current appraisals of mothers than the Mother Appraisal Down condition $(M=3.02, S D=1.30), t(169)=4.39, p<$
$.001, d=.669$. Notice that this effect size is lower than the equivalent in Experiment $1(d=1.08)$, which did not assess memory of love prior to the experimental manipulation. This raises the speculative question as to whether taking pretest measures make current appraisals relatively less malleable.

\section{Hypothesis 2: Did the Manipulation Change Memories of Love? \\ With our pretest-posttest design, for} Hypothesis 2 to hold, we should find a significant interaction between Session (pretest posttest) and Condition (Mother Appraisal Up, Mother Appraisal Down). We first examined the details of the patterns of results within each Time Period (Grades 1, 6, and 9 ) in detail — which also allowed us to compare effect sizes to Experiment 1 . Then we conducted an ANOVA that combined all Time Periods to test the hypotheses overall.

Figure 5 shows the effects of the appraisal conditions on MLPQ subscale scores. In the Supplemental Material, we document mixed ANOVAs with a within-subjects independent variable set as Session (pretest, experiment 8 weeks later) and a between-subjects independent variable as experimental Condition (Mother Appraisal Up, Mother Appraisal Down) on the dependent variable memory of love during first grade (and two separate ANOVAs examining memory of love for sixth and ninth grade). Summarizing these results, we found the effect size of the difference between the Mother Appraisal Up and Mother Appraisal Down conditions to be $d=.261$ for Grade 1 (compare to $d$ $=.501$ in Experiment 1), $d=.311$ for Grade 6 (the equivalent effect size in Experiment 1 was $d=$ .413 ), and $d=.358$ for Grade 9 (the equivalent effect size in Experiment 1 was $d=.362$ ). 

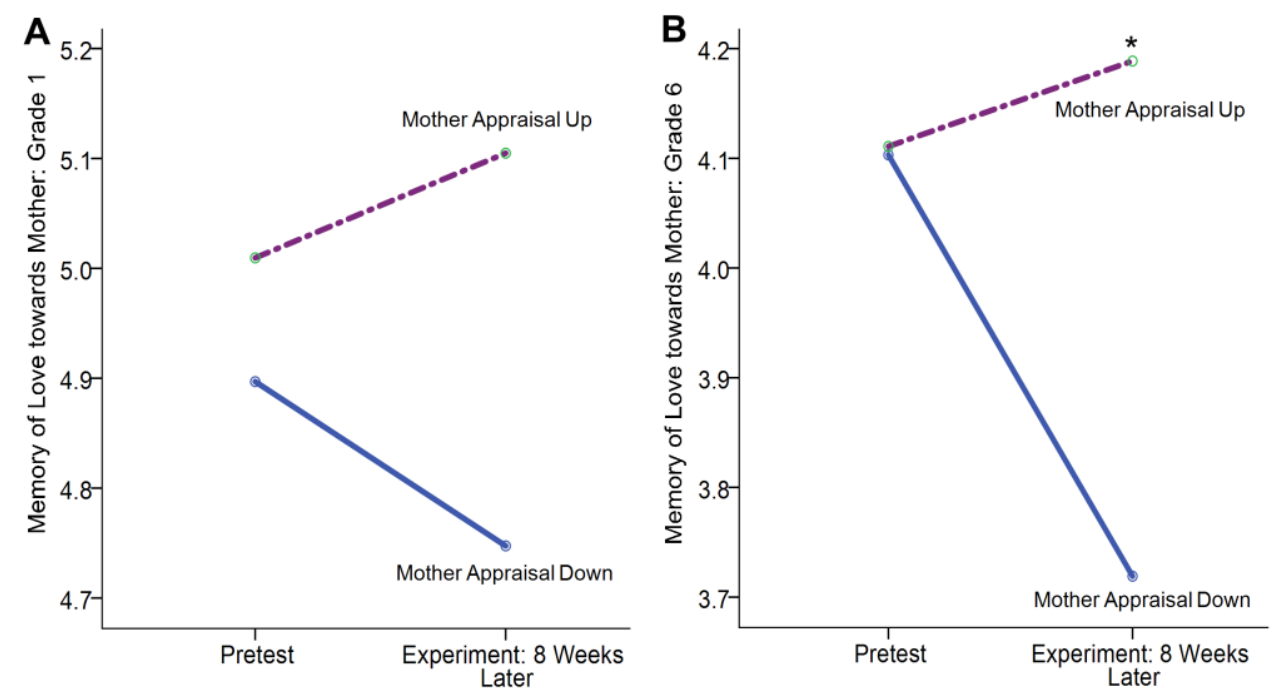

Figure 5. The effect of appraisal condition at pretest and immediately after the experimental manipulation on memory of love towards mothers (MLPQ) subscales Grade 1 (A), Grade 6 (B), Grade 9 (C), and on current feelings of love at pretest and memory of that love at pretest after the experimental writing
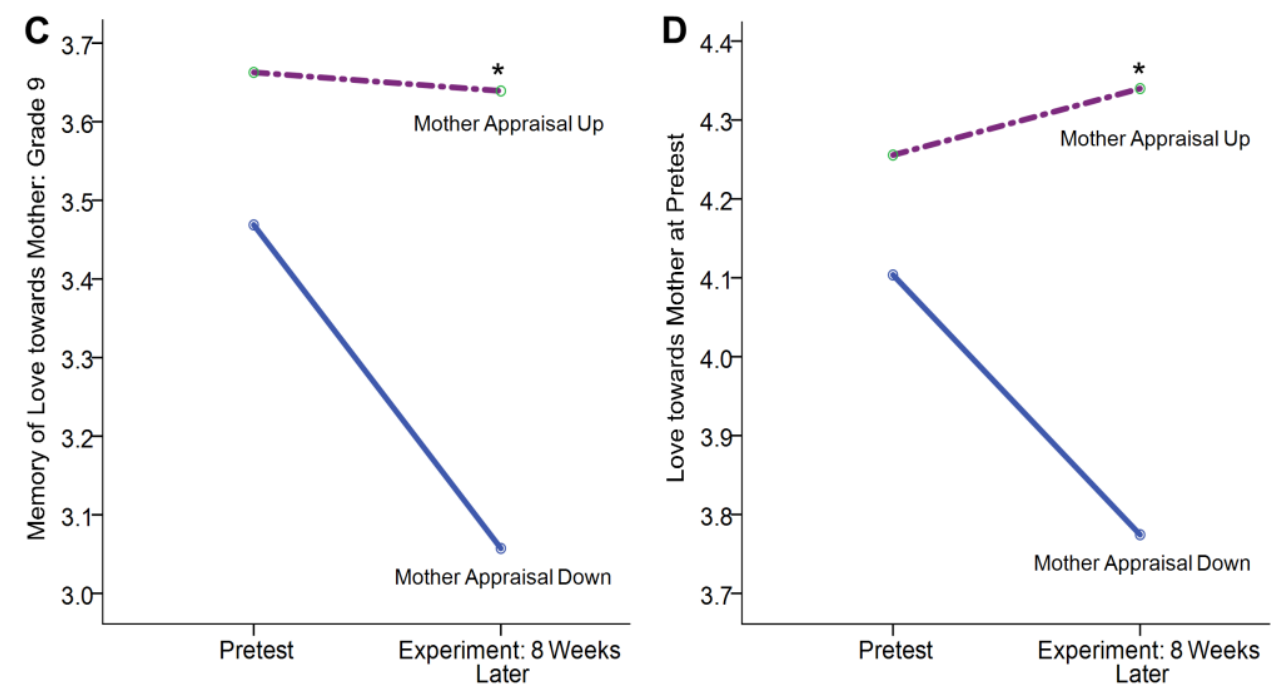
prompts 8 weeks later (D). Asterisks indicate that the Mother Appraisal Up condition is significantly higher than the Mother Appraisal Down condition at that time point for that MLPQ subscale (independent samples $t$-test $p$ values): ${ }^{*} p<.05$.

Overall Combined ANOVA. We conducted an ANOVA with two within-subjects variables: Session (pretest, experiment) and Time Period (in childhood: Grades 1, 6, and 9), and one between-subjects factor: Condition (Mother Appraisal Up, Mother Appraisal Down), with memory of love towards mothers in childhood at the outcome measure. We found a non-significant main effect for Session $F(1,199)=3.52, p=.062, \eta_{\mathrm{p}}{ }^{2}=$ .017. We found a main effect for Time Period, $F(2$, 398 ) $=268.96, p<.001, \eta_{\mathrm{p}}{ }^{2}=.575$ (memory of love was higher in early childhood compared to later childhood). And we found a significant interaction between Session and Condition, $F(1,199)=6.80, p$ $=.010, \eta_{\mathrm{p}}^{2}=.033$.

Because we found a significant interaction between Session and Condition in the combined ANOVA, we reject the alternative hypothesis that Experiment 1's results were due to pre-existing differences between groups. Our results support the hypothesis that our appraisal conditions do influence memory of love towards mothers.

Pretest Measures of Current Love Recalled Eight Weeks After the Experiment. A mixed ANOVA with pretest current feelings of love (and the memory of that 8 weeks later) as the DV revealed no main effect for Time or Condition, but a significant interaction (Time*Condition: $p=.031$; Figure 5: D). This suggested that pretest feelings of love were later recalled with a bias according to appraisal condition. This was additional evidence for Hypothesis 2, and with this measure (unlike memory of childhood) we have an accurate measure of the original feelings of love.

\section{Hypothesis 3: Did the Manipulation Change Current Feelings of Love?}

Here we test whether current feelings of love change from pretest to after the experiment. We conducted a mixed ANOVA with 
Session(pretest, posttest) as the within-subjects variable, Condition (Mother Appraisal Up, Mother Appraisal Down) as the between-subjects variable, and current feelings of love as the outcome variable. If appraisal conditions influence current feelings of love, as Hypothesis 3 posits, we should find an interaction between Session and Condition. There was no main statistically significant effect for Session, $F(1,169)=0.06, p=.937, \eta_{\mathrm{p}}{ }^{2}<.001$. The main effect for Condition not statistically significant, $F(1,169)=1.95, p=.165, \eta_{\mathrm{p}}{ }^{2}=.011$.

However, the interaction between Session and Condition was statistically significant, $F(1,169)=$ $4.79, p=.030, \eta_{\mathrm{p}}{ }^{2}=.027$. These results are examined in more detail in the Supplemental Material (p. 8-9). These results support Hypothesis 3: that appraisal condition influenced current feelings of love (via an interaction between condition and pre and posttest measures of current love).

\section{Hypothesis 4: Statistically Adjusting for Mood.}

In order to investigate the extent to which current cognitive appraisals or current mood explain the results, we examined the extent to which these variables were associated with the experimental effect. We performed an ANCOVA with memory of love as the dependent measure, Session (pretest, posttest) and childhood Time Period (Grade 1, 6, 9) as within-subjects factors, Condition as a between subject factor, and three covariates: posttest measures of cognitive appraisals, positive mood, and negative mood (PANAS subscales). The following results, therefore are those after statistically adjusting for current appraisals (a measure of the IV) and mood. There was a main statistically significant effect for Session, $F(1,165)$ $=5.36, p=.022, \eta_{\mathrm{p}}^{2}=.031$. The main effect for Condition became not statistically significant when adjusting for the covariates, $F(1,165)=2.49, p=$ $.116, \eta_{\mathrm{p}}^{2}=.015$. The interaction between Session and Condition remained statistically significant, $F(1,169)=5.01, p=.027, \eta_{\mathrm{p}}^{2}=.029$. Most relevant to Hypothesis 4, posttest current appraisal of mother was the strongest covariate predictor, $F(1,165)=$ $61.7, p<.001, \eta_{\mathrm{p}}{ }^{2}=.272$. Posttest positive mood was not a significant predictor, $F(1,165)=1.33, p$ $=.250, \eta_{\mathrm{p}}{ }^{2}=.008$, and posttest negative mood was also not a significant covariate predictor, $F(1,165)$ $=0.26, p=.610, \eta_{\mathrm{p}}^{2}=.002$. The Supplemental Material (p. S9) provides further statistical tests establishing that Hypothesis 4 was supported whichever time-period of childhood is set as the outcome measure. In support of Hypothesis 4, current cognitive appraisals of the mother explained the experimental effect of condition on memory of love better that positive or negative mood. Mediation models using the PROCESS models supported these results - mood was not a significant mediator of the relationship between appraisal condition and memory of love or current feelings of love (see Supplemental Materials, p. S11).

\section{Hypothesis 5: Did the Effects Endure?}

We examine whether the effects of the experiment endured eight weeks after the experiment. In analyses detailed in the Supplemental Material (p.9-10) we found that in Session 3 ( 8 weeks after the experiment) the effect of the experiment had begun to fade and the difference between conditions had become statistically non-significant on all of these variables: current appraisals of mothers $(p=.039, d=.246)$, memory of love towards mothers (Grade 1: $p=$ $.160, d=.217$; Grade 6: $, p=.178, d=.209$; Grade 9: $, p=.215, d=.193$ ), and current feelings of love $(p=.578, d=.095)$.

\section{General Discussion}

We set out to investigate whether we could change current appraisals towards a parent, and whether that would lead to changes in memory of love towards that parent. We developed writing prompts that successfully changed participants' current cognitive appraisals of their mothers on attributes relevant to participants' needs and goals (Hypothesis 1). We used these experimental manipulations to demonstrate that memories of love were systematically distorted as current appraisals change (Hypothesis 2). Current feelings of love towards mothers was also changed (Hypothesis 3). We found that cognitive appraisal was a much stronger predictor of these effects than were positive or negative mood (Hypothesis 4). These changes appeared resistant to change for at least four weeks, and after eight weeks the effects of the experiment appeared to have begun to fade (Hypothesis 5). To address concerns that these results were due to pre-existing differences between participants, in the second experiment we used a pretest-posttest design and confirmed that our experimental manipulation (writing prompts) are likely causing the changes in memory of love for mothers.

Scientific Implications: Theory and Mechanisms 
This research has scientific value because it adds experimental evidence to the theory that memory of emotion is partially affected by current cognitive appraisals. Put another way changes in appraisals can bias memory of emotions. Levine (1997) appears to be the first to frame this theory in these terms, and further research has incrementally added evidence since then (e.g., Levine et al., 2001; Levine et al., 2005; Safer et al., 2002; Safer et al., 2001). While maintaining much of the ecological validity of past studies, our study utilized controlled bidirectional experimental manipulations of current appraisals, and found support for the theory. This contribution was explored in Hypothesis 2, which found the effect of appraisal condition on memory of emotion, and well as Hypothesis 4, which confirmed our measure of appraisal was the strongest mediating variable. We also found some support for the more general theory of cognitive appraisal theory of emotions (Schachter \& Singer, 1962; Arnold, 1960; Lazarus, 1991; Scherer, Schorr, \& Johnstone, 2001), with our finding that current emotion appeared to change in response to appraisal manipulations (Hypothesis 3).

Alternative Explanations and

Mechanisms. There are possible alternative explanations to why our manipulations affected memory of love. For example, one might wonder whether appraisals of mothers varied between conditions was because the writing prompts elicited episodic memories of positive of negative events connected to the mother, or some other specific mechanism. The writing prompts may have resulted in making certain positive memories more available to memory (Schwarz, Bless, Strack, Klumpp, Rittenauer-Schatka, \& Simons, 1991), perhaps leading to overestimation of strength and frequency. Such specific mechanisms can be investigated in future research. These are specific sub-mechanisms that would explain the mechanisms at a different level of analysis, though those explanations would not necessarily negate the broader general theory we use in this article (Figure 1).

Another alternative explanation is that our manipulations changed current mood, and that change could explain the change in memory of emotion. We tested that in Hypothesis 4 of the current study, and mood was not as large a predictor of current cognitive appraisals (consistent also with a prediction in Levine, 1997). Although another possible explanation of the causal factor in changes in memory of emotions is current emotions, current cognitive appraisals are theorized to be the major cause of current emotions. Current cognitive appraisals and current emotions are so tightly bound together that attempting to tease them apart may be difficult. For that reason, a cognitive appraisal theory of emotions leads us to frame the cause of the effect in our experiment as appraisals because we think of appraisals as a preceding cause of current emotions, and as a partial cause of memory of emotions (see the model guiding this framework in Figure 1).

In addition, we might wonder what specific subtypes of appraisals or cognitions are most responsible for the effects we found. It would be interesting to tease apart which appraisals and/or social psychological factors most explains our results in future research. Nevertheless, these changes in appraisals might be considered to fall under the general umbrella of changes of cognitive appraisals of the environment, which includes appraisals related to self, agents, and environment.

\section{Practical Implications}

The current experiment expands the research into the practically important area of childhood memories of love once felt towards parents. We found that even a brief experiment had an effect that appeared to endure for four or more weeks (Hypothesis 5). These findings may have parallel real-life implications, ranging from situations where parents might be reappraised, whether that be in everyday life, therapy, or during legal disputes.

General Implications. In our day to day lives, there are many possible ways we might reappraise our parents. To give several examples, we can change our current appraisals of a parent if: we hear negative information about a parent, the parent becomes more or less generous, warm, or supportive, we have children of our own, we see parents with grandchildren, the parent changes with old age, we learn about the contents of a will, or they pass away. There is a danger that our memories of childhood may be partially distorted in the direction of those reappraisals. Dissemination our findings is important because if the public are aware of the processes that have been illuminated in our research, they may be better able to counteract these memory biases. There is a potential that the public could better understand that they may be over- or under-estimating the love and other emotions they once felt towards parents. 
Clinical Psychology Implications. These

findings are important to consider by psychotherapists, counsellors, and potential clients. The early beginnings of psychotherapy were rooted in the reevaluation of parents (e.g., Freud, 1953), and reappraisal of parents may continue to be elicited today by some self-help books and therapies. Any resulting memory distortion of childhood emotion may be problematic.

Nevertheless, in some rare circumstances, changes in memory and the parental relationship may be beneficial and ethical. For example, if the client has previously reappraised their parent inaccurately in the negative direction, a positive raising of appraisals may restore positive memories of emotion, as well as potentially improve the relationship. For this purpose, journal writing in response to prompts that resemble our appraisal up manipulation might be tested in clinical settings (though the purpose of our prompts was to change current appraisals for experimental purposes, not to create a treatment). Maintaining or preserving an accurate memory of childhood in therapies would be our recommendation, though it is a point of philosophy whether positive reappraisals of parents should be used to increase positive memories and improve the parent off-spring relationship.

Whatever the choice of the client and therapist is, all clients should be informed about how memories of emotions towards parents can be biased.

We would be remiss if we did not relate this research to the false memory controversy that begun in the 1990s that shone a light on the possibility of memory distortions in psychotherapies (Loftus, 1993) — a problem that may be ongoing (Patihis, Ho, Tingen, Lilienfeld, \& Loftus, 2014; Patihis \& Pendergrast, 2018). Our findings highlight the a previously underdiscussed type of memory distortions of childhood that does not involve episodic false memories. Instead, we raise the possibility of a different problem to be considered in therapies that reappraise childhood or parents: the distortion of childhood memories of emotions. This type of distortion could occur with therapists regardless of their beliefs about repressed memory. Even in therapies that don't recover false memories , reappraising the situation surrounding real childhood events, or reappraising the parent themselves, may subtly distort memories of emotions in childhood. The distortion of memories of emotion may explain psychotherapy cases where the client did not generate episodic false memories, yet still became estranged from their parent.

Implications for Legal Cases. Reappraisals of a parent or person could be brought about by divorce, custody legal disputes, and other legal cases. For example, during a divorce, downward reappraisals may negatively impact how the person remembers the love towards that parent in the years before the divorce. In such legal cases, reports of the emotions felt towards a parent before the event can be important in the expressed preferences and memories of the child, and may affect the legal decision. In addition, our research might inform cases where it is possible that a plaintiff reappraised the meaning of an event that did happen-if they come to reappraise the situation and/or the parent's character severely. The research on the malleability of memory for emotion could also be applied to legal disputes between non-related individuals. Recall of emotions and sensations, such as recall of duress, distress, or pain, surrounding an alleged crime can sometimes be central to legal cases.

\section{Ethical Considerations}

There is a question of reaching a balance between the gain to society for uncovering this knowledge and changing current appraisals of parents in our studies. In reply to this concern: no deception was used in the study - we did not give any post event misleading information about their lives or parents. Instead, we asked participants to write about real recent experiences, which has precedents in psychology research in journal writing in real life. In addition, though the writing prompts changed current appraisals of mothers, and subsequent memory of love ratings, the change was subtle and not a large deviation in the means compared to the full range of the Likert-type scale. In other words, those in the appraisal down conditions reported appraisals of their mothers high on the Likert scale, and only moderately lower than the appraisal up condition. In addition, over a period of eight weeks after the studies, we found that the subtle effects on those appraisals had begun to fade (Experiment 2, Hypothesis 5), presumably because the content of participants' written responses fade over time.

\section{Generalization to Other Emotions and Targets}

These specific results regarding memory of love and parents, may generalize to other emotions and targets. For example, when people reappraise 
spouses or partners, they may misremember memories of love during the years before the reappraisal. Parents may reappraise their offspring as they age and that may bias their memory of love they felt towards the child in the first few years of the child's life. We expect that the reappraisal of parents leads to changes in memories of other emotions too, such as sadness, anger, and happiness. Indeed, our target emotion of love was chosen not because it would be the only emotion affected by reappraisal, but because we considered it sufficiently valuable to our autobiographical memory (and we wouldn't want to diminish it in therapy or in life).

\section{Limitations}

This research has some limitations. For example, subjects in the experimental studies participated online using AMT, and not in a controlled laboratory setting. That lack of environmental control raised the possibility of introducing statistical noise into the experiments that might obscure real effects. Nevertheless, it appears such potential noise may have been evenly distributed between experimental conditions because the predicted expected effect of appraisal on memories of love emerged clearly and in keeping with previous research and theory. Using AMT participants for experimentation had important advantages over experimentation with undergraduates. The higher average age in our AMT samples may have been beneficial during our experimental manipulations because they have more varied past experience of their mother to write about - both positive and negative - compared to college students. Indeed, in preliminary pilot studies we struggled to find a manipulation that consistently affected the IV (current appraisals) in undergraduate samples. It has also been shown that AMT samples are more representative in some respects compared to undergraduates (see Buhrmester, Kwang, \& Gosling, 2011; Gosling, Vazire, Srivastava, \& John, 2004). In addition, using TurkPrime.com (Litman, Robinson, \& Abberbock, 2017) in combination with AMT facilitated effective collection of longitudinal data of three time-points with acceptable attrition rates. Another limitation is that it is unclear whether our results will extend to fathers and other target people. Nevertheless, we hypothesize that these processes will occur in other close relationships (cf.
Safer et al., 2001), and future research in this area is warranted.

\section{Summary}

We demonstrated that both current feelings of love and childhood memory of love towards mothers can be systematically distorted. Our findings are consistent with adaptations of the cognitive appraisal theory of emotions. Our experimental design incrementally adds evidence to the theory that changes in cognitive appraisals partially cause changes in memory of emotion. These results could potentially change how we all view precious aspects of childhood autobiographical memories. Our research measured the potential side effects of reappraising parents, and such reappraisal may occur in some psychotherapies. It therefore is useful research for the public to consider when choosing a therapy type, navigating therapy, or evaluating self-help books that may encourage reappraisals of parents. Love for ones' parents has been a timeless and precious part of the human experience throughout history, and it will remain a centrally important part of life for all future generations of humans. That memory of love is malleable is an uncomfortable but important finding.

\section{References}

Arnold, M. B. (1960). Emotion and Personality. New York: Columbia University Press.

Bartlett, F. C. (1932). Remembering: A Study in Experimental and Social Psychology. New York: Cambridge University Press.

Buhrmester, M., Kwang, T., \& Gosling, S. D. (2011). Amazon's Mechanical Turk: A new source of inexpensive, yet high-quality, data? Perspectives on Psychological Science, 6, 3-5.

Freud, S. (1953). The Standard Edition of the Complete Works of Sigmund Freud, 2. London, UK: Hogarth Press.

Campos, B., Shiota, M. N., Keltner, D., Gonzaga, G. C., \& Goetz, J. L. (2013). What is shared, what is different? Core relational themes and expressive displays of eight positive emotions. Cognition \& Emotion, 27, 37-52.

Crombag, H. F., Wagenaar, W. A., \& Van Koppen, P. J. (1996). Crashing memories and the problem of 'source monitoring'. Applied Cognitive Psychology, 10, 95-104.

Dykas, M. J., Woodhouse, S. S., Jones, J. D., \& Cassidy, J. (2014). Attachment-related biases in adolescents' memory. Child development, 85, 2185-2201.

Edelstein, R. S. (2006). Attachment and emotional memory: investigating the source and extent of avoidant memory impairments. Emotion, 6, 340-345. 
Edelstein, R. S., Ghetti, S., Quas, J. A., Goodman, G. S., Alexander, K. W., Redlich, A. D., \& Cordón, I. M. (2005). Individual differences in emotional memory: Adult attachment and long-term memory for child sexual abuse. Personality \& Social Psychology Bulletin, 31, 1537-1548.

Faul, F., Erdfelder, E., Lang, A. G., \& Buchner, A. (2007). G* Power 3: A flexible statistical power analysis program for the social, behavioral, and biomedical sciences. Behavior Research Methods, 39, 175191.

Gosling, S. D., Vazire, S., Srivastava, S., \& John, O. P. (2004). Should we trust web-based studies? A comparative analysis of six preconceptions about internet questionnaires. American Psychologist, 59, 93-104.

Hayes, A. F. (2012). PROCESS: A versatile computational tool for observed variable mediation, moderation, and conditional process modeling [White paper].

Retrieved from http://www.afhayes.com/ public/process2012.pdf

Hayes, A. F. (2013). Introduction to mediation, moderation, and conditional process analysis: A regression-based approach. New York: Guilford Press.

Hovasapian, A., \& Levine, L. J. (2016). Reappraisal mitigates overestimation of remembered pain in anxious individuals. Cognition \& Emotion, 30, 1222-1231.

Hyman, I. E., Husband, T. H., \& Billings, F. J. (1995). False memories of childhood experiences. Applied Cognitive Psychology, 9, 181-197.

Katz, A. N. (1989). Autobiographical memory as a reconstructive process. Canadian Journal of Psychology, 43, 512-517.

Keuler, D. J., \& Safer, M. A. (1998). Memory bias in the assessment and recall of pre-exam anxiety: how anxious was I? Applied Cognitive Psychology, 12, S127-S137.

Lazarus, R. S. (1991). Cognition and motivation in emotion. American Psychologist, 46, 352-367.

LeDoux, J. E. (1992). Emotion as memory: Anatomical systems underlying indelible neural traces. In S. Christianson (Ed.), The handbook of emotion and memory: Research and theory (pp. 269-288). Hillsdale, NJ: Erlbaum.

Levine, L. J. (1997). Reconstructing memory for emotions. Journal of Experimental Psychology: General, 126, 165-177.

Levine, L. J., Lench, H. C., \& Safer, M. A. (2009). Functions of remembering and misremembering emotion. Applied Cognitive Psychology, 23, 1059-1075.

Levine, L. J., Prohaska, V., Burgess, S. L., Rice, J. A., \& Laulhere, T. M. (2001). Remembering past emotions: The role of current appraisals. Cognition \& Emotion, 15, 393-417.

Levine, L. J., Whalen, C. K., Henker, B., \& Jamner, L. D. (2005). Looking back on September 11, 2001: Appraised impact and memory for emotions in adolescents and adults. Journal of Adolescent Research, 20, 497-523.

Litman, L., Robinson, J., \& Abberbock, T. (2017). TurkPrime.com: A versatile crowdsourcing data acquisition platform for the behavioral sciences. Behavior Research Methods, 49, 433-442.

Loftus, E. F. (1993). The reality of repressed memories. American Psychologist, 48, 518-537.

Loftus, E. F. (2005). Planting misinformation in the human mind: A 30-year investigation of the malleability of memory. Learning \& Memory, 12, 361-366.

Loftus, E. F., Miller, D. G., \& Burns, H. J. (1978). Semantic integration of verbal information into a visual memory. Journal of Experimental Psychology: Human Learning \& Memory, 4, 19-31.

Loftus, E. F., \& Pickrell, J. E. (1995). The formation of false memories. Psychiatric Annals, 25, 720-725.

Patihis, L., Frenda, S. J., LePort, A. K., Petersen, N., Nichols, R. M., Stark, C. E., ... \& Loftus, E. F. (2013). False memories in highly superior autobiographical memory individuals. Proceedings of the National Academy of Sciences, 110, 20947-20952.

Patihis, L., Herrera, M. E., Huff, M. J., \& Arnau, R. C. (in press). Memory of Love towards Parents Questionnaire: Development and psychometric evaluation. Psychological Reports. https://doi.org/10.1177/0033294118809929

Patihis, L., Ho, L. Y., Tingen, I. W., Lilienfeld, S. O., \& Loftus, E. F. (2014). Are the "memory wars" over? A scientist-practitioner gap in beliefs about repressed memory. Psychological Science, 25, 519-530.

Patihis, L., Jackson, C. E., Diaz, J. C., Stepanova, E. V., \& Herrera, M. E. (in press). Black American college students report higher memory of love for mothers in childhood than White students. Psychological Reports, 1-19. https://doi.org/10.1177/0033294118772549

Patihis, L., \& Loftus, E. F. (2016). Crashing memory 2.0: False memories in adults for an upsetting childhood event. Applied Cognitive Psychology, 30, 41-50.

Patihis, L., \& Pendergrast, M. H. (in press). Reports of recovered memories of abuse in therapy in a large age-representative US national sample: Therapy type and decade comparisons. Clinical Psychological Science, 1-19. https://doi.org/10.1177/2167702618773315

Porter, S., Yuille, J. C., \& Lehman, D. R. (1999). The nature of real, implanted, and fabricated memories for emotional childhood events: Implications for the recovered memory debate. Law and Human Behavior, 23, 517-537.

Roediger, H. L., \& McDermott, K. B. (1995). Creating false memories: Remembering words not presented in lists. Journal of Experimental Psychology: Learning, Memory, \& Cognition, 21, 803-814.

Ross, M. (1989). The relation of implicit theories to the construction of personal histories. Psychological Review, 96, 341-357.

Safer, M. A., Bonanno, G. A., \& Field, N. P. (2001). "It was never that bad": Biased recall of grief and long-term adjustment to the death of a spouse. Memory, 9, 195203.

Safer, M. A., Levine, L. J., \& Drapalski, A. L. (2002). Distortion in memory for emotions: The contributions of personality and post-event 
knowledge. Personality \& Social Psychology Bulletin, 28, 1495-1507.

Schachter, S., \& Singer, J. (1962). Cognitive, social, and physiological determinants of emotional state. Psychological Review, 69, 379-399.

Scherer, K. R., Schorr, A., \& Johnstone, T. (Eds.). (2001). Appraisal processes in emotion: Theory, methods, research. New York: Oxford University Press.

Schwarz, N., Bless, H., Strack, F., Klumpp, G., RittenauerSchatka, H., \& Simons, A. (1991). Ease of retrieval as information: Another look at the availability heuristic. Journal of Personality \& Social Psychology, 61, 195-202.

Shaver, P. R., Morgan, H. J., \& Wu, S. (1996). Is love a "basic" emotion? Personal Relationships, 3, 81-96.
Shaw, J., \& Porter, S. (2015). Constructing rich false memories of committing crime. Psychological Science, 26, 291-301.

Smith, W. B., \& Safer, M. A. (1993). Effects of present pain level on recall of chronic pain and medication use. Pain, 55, 355-361.

Smith, W. B., Gracely, R. H., \& Safer, M. A. (1998). The meaning of pain: cancer patients' rating and recall of pain intensity and affect. Pain, 78, 123-129.

Watson, D., Clark, L. A., \& Tellegen, A. (1988). Development and validation of brief measures of positive and negative affect: the PANAS scales. Journal of Personality and Social Psychology, 54, 1063-1070.

Wilson, A. E., \& Ross, M. (2003). The identity function of autobiographical memory: time is on our side. Memory, 11, 137-149. 


\section{Pilot Study 1}

In this correlational pilot study we investigated the size of the relationships between current appraisals of parents (both mothers and fathers in separate items) and both memory of love in childhood, as well as current feelings of love. This data was also used, in conjunction with nine other samples, to evaluate the psychometrics properties of our scale, the Memory of Love towards Parents Questionnaire (MLPQ; Patihis, Herrera, Huff, \& Arnau, in press).

\section{Methods}

\section{Participants}

Undergraduates $(N=280)$ from a university in the south of the United States participated for course credit. No differences on MLPQ subscales were found between those participating online and in the laboratory (Patihis et al., in press). The mean age was $21.5(S D=5.6)$, with $80.7 \%$ female. Ethnicity was distributed as follows: $44.6 \%$ White, $44.3 \%$ Black or African American, 5.4\% Asian, 2.9\% Latino or Hispanic, and 2.8\% other ethnicities. Mean self-reported socioeconomic status (SES), on a scale from one to 10, was $4.93(S D=1.6)$.

\section{Procedure and Materials}

The procedure for involved some subjects $(n=179)$ participating in lab at a preordained appointment time, while others participated online also at set appointment times $(n=101)$. The procedure for Sample 2 also involved participating in a brief second session exactly one week after the first so that test-retest data for the MLPQ could be obtained. The study took about 1 hour, after which participants read a debriefing sheet and were compensated with course credit.

The materials consisted of demographic questions, parent background questions, current positive and negative affect (PANAS; Watson, Clark, \& Tellegen, 1988), current appraisal questions (see Appendix S1; Cronbach $\alpha=.936$ for appraisal of mother's attribute), and the 
MLPQ (see Appendix S2; Cronbach $\alpha$ s $=.975, .980, .980, .987$; for Grade 1, 6, 9, and Current respectively). Other measures were collected after this that are not analyzed in the present article (e.g., scales assessing depression, anxiety, potential trauma).

\section{Results and Discussion}

Initial correlational data in an undergraduate sample $\left(N=280 ; M_{a g e}=21.5 \mathrm{y}\right)$ indicated medium to strong correlations between current appraisals of mother's attributes and memory of love in childhood $\left(1^{\text {st }}\right.$ grade: $r=.611 ; 6^{\text {th }}$ grade: $r=.639 ; 9^{\text {th }}$ grade: $\left.r=.603\right)$; and corresponding moderate correlations with fathers as the target parent $(r \mathrm{~s}=.357, .303, \& .354$, respectively; all ps $<.001)$. In parallel, using this sample and Amazon Mechanical Turk (AMT) samples, we evaluated the psychometrics of the dependent measure - the MLPQ-and found high internal reliability ( $\alpha$ 's > .95), a single factor, and factorial validity (e.g., between subscales, with attachment measures; Patihis et al., in press). Although we found statistically significant correlations between appraisal and MLPQ subscales, we were uncertain whether these relationships were causal, so next we developed experimental designs to attempt to subtly manipulate current appraisals of a parent. Due to the stronger relationship between the MLPQ subscales and appraisals within mothers, we focused subsequent experimental approaches utilizing mothers as the target parent.

\section{Pilot Study 2}

In pretesting of materials, one undergraduate and two Amazon Mechanical Turk (AMT) samples were utilized to test a combination of vignettes and writing prompts and their effect on current appraisals. We found that our vignettes shifted appraisals only slightly and nonsignificantly in the desired direction, and were less effective than writing prompts.

\section{Method}




\section{Participants}

In the final pilot, we identified materials that appeared to produce the desired statistically significant changes in appraisals in an AMT sample $(N=302)$ of mean age $35.3(S D=10.5$; range 19-79), with 77.2\% (233) female, 22.2\% (67) male, and .7\% (2) choosing “other (please specify)." Ethnicity was self-reported as: 7.3\% (22) Hispanic or Latino, with 92.4\% (279) not Hispanic or Latino. Race was distributed as: 84.8\% (256) White, 6.6\% (20) Black or African American, 5.0\% (15) Asian, 4.3\% (12) American Indian or Alaska Native, 0.3\% (1) Native Hawaiian or Pacific Islander, and $2.0 \%$ chose other.

\section{Procedure and Materials}

The materials and procedure involved first presenting demographic questions, then randomly assigning participants into one of four conditions shown: Mother Appraisal Up, Mother Appraisal Down, Teacher Appraisal Up, and Null (for materials see Appendix S3). After this experimental assignment, all participants completed questions assessing current appraisal of their mothers (Appendix S1). The Teacher Appraisal Up condition was a control condition to compare to both Mother Appraisal Up, and Mother Appraisal Down. After completing the study participants were debriefed and automatically given a secret code for payment of \$.25 on AMT. The study took approximately 10 minutes.

\section{Results and Discussion}

We investigated a number of possible manipulations, with both undergraduate and AMT samples, ranging from vignettes (which were not effective) to various writing prompts. We eventually found a series of writing prompts that reliably changed current appraisals of mothers in AMR samples, but these writing prompts were less reliable in moving the IV in the (younger) student samples. These experimental groups included writing prompts that asked participants to 
give several recent examples of when their mother showed warmth, competence, good guidance, and so on (Mother Appraisal Up condition) — the other experimental group asked participants to write about examples then their mother showed a lack of these traits (Mother Appraisal Down). We also utilized two control groups. We found a significant difference in current appraisals between the Mother Appraisal Up and Appraisal Down conditions, $t(134)=3.79, p<.001$. This significant difference remained when controlling for current positive and negative affect (PANAS subscales; Watson, Clark, \& Tellegen, 1988). The difference between both control groups $($ Null = no material; Teacher Appraisal Up) and the Appraisal Up condition was statistically nonsignificant, but the control groups were significantly higher than the Appraisal Down condition (LSD post hoc: $p$ s $<.001$; see Figure 1, A). We concluded that the most reliable manipulation of current appraisals of mothers would be found by utilizing the Mother Appraisal Up and Mother Appraisal Down conditions, noting that Mother Appraisal Down appeared to have the most effect - and this conclusion was supported in the experiments that followed (described in the main article). 


\section{Experiment 1 Supplemental Results \& Discussion}

Hypothesis 1. The experimental conditions had a similar effect on current appraisals of the mother as the pilot study (see Figure 2), with the Mother Appraisal Up condition scoring significantly higher $(M=4.11, S D=0.96)$ than Mother Appraisal Down $(M=2.87, S D=1.32)$, $t(146)=6.54, p<.001$, Cohen's $d=1.08$. This effect held when controlling for mood: in an ANCOVA with PANAS negative and positive subscales as covariates, appraisal condition was still a strong predictor of the outcome variable current appraisals of mother, $F(1,144)=17.9, p<$ $.001, \eta_{\mathrm{p}}{ }^{2}=.220$. As illustrated in Figure 2, and consistent with our pilot studies, the control conditions had current appraisal of mother mean scores between the mean scores for the two experimental groups. The manipulations effected the IV bi-directionally, with the Mother Appraisal Down condition a having a stronger and more consistent effect than the Mother Appraisal Up condition (consistent with our pilot study).

Hypothesis 4. We used a PROCESS macro in SPSS for mediation (using model 6 for multiple mediators, with 5000 iterations), with the model given in the diagram below.

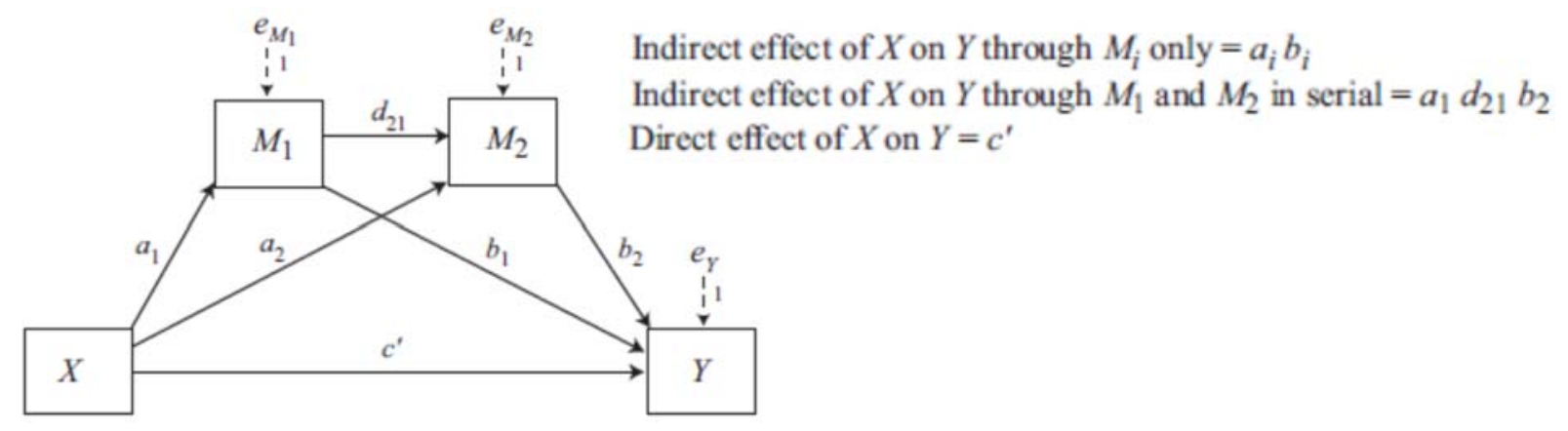

Memory of Love First Grade. with the memory of love for first grade as the dependent measure (y), and Condition (dichotomized: Mother Appraisal Up, Mother Appraisal Down) as the independent variable $(\mathrm{x})$, and positive and negative mood as mediators $\left(\mathrm{M}_{1}, \mathrm{M}_{2}\right)$, we the total effect of $\mathrm{x}$ on $\mathrm{y}$ was significant $(t=3.05, p=.003, c=.651)$, the direct effect of $\mathrm{x}$ on $\mathrm{y}$ as 
significant $\left(t=2.54, p=.012, c^{\prime}=.502\right)$ and the total indirect effect of the mediators (negative and positive mood) was non-significant (Standardized total indirect effect of $\mathrm{M}_{1}$ and $\mathrm{M}_{2}=.150$ [$.031, .360])$. Mood did not mediate the experimental effect on memory of love for first grade.

Memory of Love Sixth Grade. Using the PROCESS mediation with the memory of love for sixth grade as the dependent measure (y), and Condition (dichotomized: Mother Appraisal Up, Mother Appraisal Down) as the independent variable (x), and positive and negative mood as mediators $\left(\mathrm{M}_{1}, \mathrm{M}_{2}\right)$, we the total effect of $\mathrm{x}$ on $\mathrm{y}$ was significant $(t=2.50, p=.014, c=.601)$, the direct effect of $\mathrm{x}$ on $\mathrm{y}$ as significant $\left(t=2.03, p=.044, c^{\prime}=.450\right)$ and the mediators (negative and positive mood) were again non-significant (Standardized total indirect effect of $\mathrm{M}_{1}$ and $\left.\mathrm{M}_{2}=.102[-.029, .246]\right)$. Mood did not mediate the experimental effect on memory of love for sixth grade.

Memory of Love Ninth Grade. Using the PROCESS mediation with the memory of love for ninth grade as the dependent measure (y), and Condition (dichotomized: Mother Appraisal Up, Mother Appraisal Down) as the independent variable (x), and positive and negative mood as mediators $\left(\mathrm{M}_{1}, \mathrm{M}_{2}\right)$, we the total effect of $\mathrm{x}$ on $\mathrm{y}$ was significant $(t=2.19, p=.030, c=.598)$, the direct effect of $\mathrm{x}$ on $\mathrm{y}$ as significant $\left(t=1.60, p=.112, c^{\prime}=.388\right)$ and the mediators (negative and positive mood) were again non-significant (Standardized total indirect effect of $\mathrm{M}_{1}$ and $\left.\mathrm{M}_{2}=.126[-.030, .284]\right)$. Although the direct effect of $\mathrm{x}$ on $\mathrm{y}$ was reduced, mood did not significantly influence the experimental effect on memory of love for ninth grade.

Current Love. Using the PROCESS mediation with current love as the dependent measure (y), and Condition (dichotomized: Mother Appraisal Up, Mother Appraisal Down) as the independent variable $(\mathrm{x})$, and positive and negative mood as mediators $\left(\mathrm{M}_{1}, \mathrm{M}_{2}\right)$, we the total effect of $\mathrm{x}$ on $\mathrm{y}$ was significant $(t=4.11, p<.001, c=1.168)$, the direct effect of $\mathrm{x}$ on $\mathrm{y}$ as 
significant $\left(t=3.67, p<.001, c^{\prime}=.946\right)$ and the mediators (negative and positive mood) were again non-significant (Standardized total indirect effect of $\mathrm{M}_{1}$ and $\mathrm{M}_{2}=. .122[-.017, .493]$ ). Mood did not mediate the experimental effect on current love.

Hypothesis 5. A mixed ANOVA with memory of love towards mothers for Grade 1 as the dependent measure, Session (Session 1: initial experiment session, Session 2: two weeks later, Session 2: four weeks later) as a within-subjects IV, and Condition (Mother Appraisal Up, Teacher Appraisal Down, Null, Mother Appraisal Up) as the between-subjects IV revealed a main effect for Condition, $F(3,199)=3.70, p=.013, \eta_{\mathrm{p}}{ }^{2}=.053$. There was no main effect for Session, $F(2,398)=0.36, p=.701, \eta_{\mathrm{p}}^{2}=.002$, and no significant interaction between Condition and Session, $F(6,398)=0.69, p=.656, \eta_{\mathrm{p}}^{2}=.010$.

A mixed ANOVA with memory of love towards mothers for Grade 6 as the dependent measure, Session as a within-subjects IV, and Condition as the between-subjects IV revealed no significant main effect for Condition, $F(3,199)=1.80, p=.148, \eta_{\mathrm{p}}{ }^{2}=.026$. There was no main effect for Session, $F(2,398)=0.14, p=.870, \eta_{\mathrm{p}}^{2}=.001$. There was a significant interaction between Condition and Session, $F(6,398)=2.74, p=.013, \eta_{\mathrm{p}}^{2}=.040$. Figure 4 (graph B) illustrates this interaction: the effect of the experiment endures into Session 2 in divergent directions depending on condition, and the effect of the initial experiment begins to fade by Session 3 (again, the direction of the fading effect dependent on whether the initial condition raised or lowered appraisals).

A mixed ANOVA with memory of love towards mothers for Grade 9 as the dependent measure, Session as a within-subjects IV, and Condition as the between-subjects IV revealed no significant main effect for Condition, $F(3,198)=1.80, p=.148, \eta_{\mathrm{p}}^{2}=.026$. There was no main 
effect for Session, $F(2,396)=1.27, p=.262, \eta_{\mathrm{p}}^{2}=.006$. There was no significant interaction between Condition and Session, $F(6,396)=1.55, p=.160, \eta_{\mathrm{p}}{ }^{2}=.023$.

A mixed ANOVA with current feelings of love towards mother as the dependent measure, Session as a within-subjects IV, and Condition as the between-subjects IV revealed a significant main effect for Condition, $F(3,200)=6.30, p<.001, \eta_{\mathrm{p}}{ }^{2}=.086$. There was no significant main effect for Session, $F(2,200)=2.12, p=.147, \eta_{\mathrm{p}}{ }^{2}=.010$. There was no significant interaction between Condition and Session, $F(6,200)=1.91, p=.130, \eta_{\mathrm{p}}{ }^{2}=.028$.

Also evident from Figure 4, putting all participants through the Mother Appraisal Up condition in Session 3 had noticeably less immediate effect on MLPQ subscale scores than the initial experimental conditions had in Session 1. We hypothesize that peoples' current appraisals and memory are most malleable and labile before they completed the MLPQ. Completing the memory of love questions may either consolidate their memory of love, or participants may remember how they previously answered the items. From our results, we also speculate that it may take longer than four weeks before MLPQ scores become labile again, so in the next experiment we increased the time period between sessions to eight weeks.

\section{Experiment 2 Supplemental Results \& Discussion}

\section{Hypothesis 2}

First Grade. Figure 5 shows the effects of the appraisal conditions on MLPQ subscale scores. We conducted a mixed ANOVA with a within subjects independent variable set as Session (pretest, experiment 8 weeks later) and a between subjects independent variable as experimental Condition (Mother Appraisal Up, Mother Appraisal Down) on the dependent variable memory of love at Grade 1. This is illustrated in Figure 5, graph A. There was no significant main effect for Session, $F(1,200)=0.13, p=.723, \eta_{\mathrm{p}}{ }^{2}=.001$, nor for Condition, $F(1$, 
$200)=1.88, p=.172, \eta_{\mathrm{p}}{ }^{2}=.009$. The interaction between Session and Condition was not statistically significant, $F(1,200)=2.56, p=.111, \eta_{\mathrm{p}}^{2}=.013$. At Session 2, after the experimental manipulation, the difference between the Mother Appraisal Up condition $(M=$ $5.10, S D=1.14, n=106$ ) was marginally, but not statistically significantly higher, than the Mother Appraisal Down condition $(M=4.74, S D=1.56, n=97), t(201)=1.87, p=.063, d=$ .261. The comparable effect size in Experiment 1, in which pretest measures were not taken before the experimental manipulation, was $d=.501$.

Sixth Grade. We conducted a mixed ANOVA with a within subjects variable set as Session and a between subject variable Condition on the outcome measure memory of love at Grade 6 (Figure 5, B). The main effect for Session was marginally not statistically significant, $F(1,200)=3.39, p=.067, \eta_{\mathrm{p}}{ }^{2}=.017$. The main effect for Condition was not statistically significant, $F(1,201)=1.51, p=.220, \eta_{\mathrm{p}}{ }^{2}=.007$. The interaction between Session and Condition was statistically significant, $F(1,201)=5.40, p=.006, \eta_{\mathrm{p}}{ }^{2}=.037$. At Session 2 , after the experimental manipulation, the difference between the Mother Appraisal Up condition $(M=$ 4.19, $S D=1.44, n=106$ ) was statistically significantly higher than the Mother Appraisal Down condition $(M=3.72, S D=1.57, n=97), t(201)=2.22, p=.028, d=.311$ (the equivalent effect size in Experiment 1 was $d=.413)$.

Ninth Grade. We conducted a mixed ANOVA with a within subjects variable set as Session and a between subject variable Condition on the outcome measure memory of love at Grade 9 (Figure 5, C). The main effect for Session was statistically significant, $F(1,200)=6.52$, $p=.011, \eta_{\mathrm{p}}^{2}=.032$. The main effect for Condition was marginally not statistically significant, $F(1,200)=3.40, p=.067, \eta_{\mathrm{p}}^{2}=.017$. The interaction between Session and Condition was statistically significant, $F(1,200)=5.18, p=.024, \eta_{\mathrm{p}}{ }^{2}=.025$. At Session 2 , after the 
experimental manipulation, the difference between the Mother Appraisal Up condition $(M=$ 3.64, $S D=1.61, n=106$ ) was statistically significantly higher than the Mother Appraisal Down condition $(M=3.06, S D=1.64, n=96), t(200)=2.54, p=.012, d=.358$ (the equivalent effect size in Experiment 1 was $d=.362$ ).

\section{Hypothesis 3}

To parse the results in the main text further, and to compare effect sizes to Experiment 1, we examined these variables in more detail. At pretest, before the experiment, current feelings of love towards the mother were not statistically significantly different between the conditions that were later assigned in the experiment eight weeks later (Mother Appraisal Up: $M=4.28, S D=$ $1.70, n=91)$ condition and the Mother Appraisal Down: $M=4.15, S D=1.92, n=84), t(173)=$ $0.50, p=.618, d=.075$. At Session 2, after the experimental manipulation, the difference between the Mother Appraisal Up condition $(M=3.90, S D=1.96, n=82)$ on current feelings of love was statistically significantly higher than the Mother Appraisal Down condition $(M=4.47$, $S D=1.61, n=89), t(169)=2.09, p=.039, d=.318($ the equivalent effect size in Experiment 1 was $d=.675)$. Hypothesis 3 is supported again by these data, but the effect in Experiment 2 appears weaker than Experiment 1. This reduction in effect size is perhaps due to the pretest measures asking participants to score their current feelings of love having an anchoring effect.

\section{Hypothesis 4}

Examining in more detail (compared to the main text) by each childhood time-period in more detail. Setting MLPQ Grade 1 as the DV, current cognitive appraisals of the mother was a statistically significant covariate $\left(p<.001, \eta_{\mathrm{p}}^{2}=.21\right)$ and positive and negative mood were not significant covariates $\left(\eta_{\mathrm{p}}^{2}<.02\right)$. Similar results were found when the DV was MLPQ Grade 6 (current appraisals: $\eta_{\mathrm{p}}^{2}=.21$; positive \& negative mood: $\eta_{\mathrm{p}}{ }^{2}<.02$ ). For MLPQ Grade 9, 
cognitive appraisals were again the largest predictor $\left(\eta_{\mathrm{p}}{ }^{2}=.271\right)$, with positive affect as a lesser covariate $\left(p=.013, \eta_{\mathrm{p}}{ }^{2}=.04\right)$, and negative affect as not statistically significant. With feelings of love towards mother at pretest (and memory of after experiment) as the DV, current appraisals of mother was a strong predictor $\left(\eta_{\mathrm{p}}^{2}=.57\right)$ with positive and negative affect as nonsignificant covariates $\left(\eta_{\mathrm{p}}^{2}<.02\right)$. Thus, Hypothesis 4 is supported whichever time-period of childhood is set as the outcome measure.

PROCESS mediation. We used a PROCESS macro in SPSS for mediation to investigate whether mood mediated the relationship between our experimental manipulation (of appraisals) and memory of love as well as current feelings of love (using model 6 for multiple mediators, with 5000 iterations).

Memory of Love First Grade. With the memory of love for first grade (taken immediately after the experimental manipulation in Session 2) as the dependent measure (y), and Condition (Mother Appraisal Up, Mother Appraisal Down) as the independent variable (x), and positive and negative mood as mediators $\left(\mathrm{M}_{1}, \mathrm{M}_{2}\right.$; taken after the experimental manipulation in Session 2), we found the total effect of $\mathrm{x}$ on $\mathrm{y}$ was $t=1.94, p=.053, c=.372$, the direct effect of $\mathrm{x}$ on $\mathrm{y}$ was $t=1.78, p=.077, c^{\prime}=.336$ and the total indirect effect of the mediators (negative and positive mood) was non-significant (partially standardized total indirect effect of $\mathrm{M}_{1}$ and $\mathrm{M}_{2}$ $=.0259[-.031, .123])$. Mood did not mediate the experimental effect on memory of love for first grade.

Memory of Love Sixth Grade. Using the PROCESS mediation with the memory of love for sixth grade grade (taken immediately after the experimental manipulation in Session 2) as the dependent measure (y), and Condition (Mother Appraisal Up, Mother Appraisal Down) as the independent variable $(\mathrm{x})$, and positive and negative mood as mediators $\left(\mathrm{M}_{1}, \mathrm{M}_{2}\right.$; taken after the 
experimental manipulation in Session 2), we found the total effect of $\mathrm{x}$ on $\mathrm{y}$ was significant $(t=$ $2.24, p=.026, c=.476)$, the direct effect of $\mathrm{x}$ on $\mathrm{y}$ was $t=1.94, p=.054, c^{\prime}=.409$, and the mediators (negative and positive mood) were again non-significant (partially standardized total indirect effect of $\mathrm{M}_{1}$ and $\left.\mathrm{M}_{2}=.044[-.008, .142]\right)$. Although the direct effect of $\mathrm{x}$ on $\mathrm{y}$ was reduced, mood was not a large mediator of the experimental effect on memory of love for sixth grade.

Memory of Love Ninth Grade. Using the PROCESS mediation with the memory of love for ninth grade (measured immediately after the experimental manipulation in Session 2) as the dependent measure (y), and Condition (dichotomized: Mother Appraisal Up, Mother Appraisal Down) as the independent variable (x), and positive and negative mood as mediators $\left(\mathrm{M}_{1}, \mathrm{M}_{2}\right.$; measured after the experimental manipulation in Session 2), we found the total effect of $\mathrm{x}$ on $\mathrm{y}$ was significant $(t=2.52, p=.012, c=.581)$, the direct effect of $\mathrm{x}$ on $\mathrm{y}$ was significant $(t=2.21$, $p=.028, c^{\prime}=.500$ ) and the mediators (negative and positive mood) were again non-significant (partially standardized total indirect effect of $\mathrm{M}_{1}$ and $\mathrm{M}_{2}=.049[-.012, .145]$ ). Mood did not mediate the experimental effect on memory of love for ninth grade.

Current Love. Using the PROCESS mediation with current love (taken in Session 2 immediately after the experimental manipulation) as the dependent measure (y), and Condition (dichotomized: Mother Appraisal Up, Mother Appraisal Down) as the independent variable (x), and positive and negative mood as mediators $\left(\mathrm{M}_{1}, \mathrm{M}_{2}\right.$; taken in Session 2 immediately after the experimental manipulation), we found the total effect of $\mathrm{x}$ on $\mathrm{y}$ was significant $(t=2.06, p=$ $.041, c=.566)$, the direct effect of $\mathrm{x}$ on $\mathrm{y}$ was $t=3.67, p=.098, c^{\prime}=.449$ ) and the mediators (negative and positive mood) were again non-significant (partially standardized total indirect effect of $\mathrm{M}_{1}$ and $\left.\mathrm{M}_{2}=.065[-.014, .162]\right)$. Mood did not mediate the experimental effect on 
current love. Although the direct effect of $\mathrm{x}$ on $\mathrm{y}$ was reduced, mood was not a large mediator of the experimental effect on current feelings of love towards the mother.

\section{Hypothesis 5}

Eight weeks after the experiment, we found that current appraisals of mother's attributes was not significantly different between the Mother Appraisal Up condition $(M=3.57, S D=1.16$, $n=72)$ and the Mother Appraisal Down condition $(M=3.27, S D=1.29, n=65), t(135)=1.44$, $p=.039, d=.246$. For comparison purposes, Cohen's $d$ was .669 on this same comparison for the measure taken immediately after the experiment in Session 2 (it was $d=.050$ at pretest in Session 1, eight weeks before the experiment. Eight weeks after the experiment, the effects of the experiment on current appraisals of mothers had begun to return to baseline.

Eight weeks after the experiment, we found that memory of love towards mothers during first grade was not significantly different between the Mother Appraisal Up condition ( $M$ $=5.04, S D=1.15, n=88)$ and the Mother Appraisal Down condition $(M=4.74, S D=1.54, n=$ $79), t(165)=1.41, p=.160, d=.217$. On memory of love towards mothers during sixth grade, Mother Appraisal Up condition $(M=4.16, S D=1.44, n=88)$ was not statistically significantly different than the Mother Appraisal Down condition $(M=3.85, S D=1.58, n=79), t(165)=$ $1.35, p=.178, d=.209$. On memory of love towards mothers during ninth grade, Mother Appraisal Up condition $(M=3.53, S D=1.58, n=88)$ was not statistically significantly different than the Mother Appraisal Down condition $(M=3.22, S D=1.60, n=79), t(165)=1.24, p=$ $.215, d=.193$. Eight weeks after the experiment, measures of memory of love had begun to return to baseline.

Eight weeks after the experiment, we found that current feelings of love towards mothers was not significantly different between the Mother Appraisal Up condition $(M=4.21, S D=1.64$, 
$n=72)$ and the Mother Appraisal Down condition $(M=4.05, S D=1.82, n=65), t(135)=0.56$, $p=.578, d=.095$. Eight week after the experiment, the experimental effects on current feelings of love towards the mother had faded. On all the outcome measures examined in Hypothesis 5, we found the effects of the experiment had begun to fade eight weeks after the experiment. 
Table S1

Descriptive Statistics of Memory of Love and Current Feelings of Love towards Mothers by Condition and Time Period: With Comparison Inferential Statistics (Experiment 1, Session 1)

\begin{tabular}{|c|c|c|c|c|c|c|}
\hline \multirow[b]{2}{*}{ Time Perioc } & \multirow[b]{2}{*}{ Condition } & \multirow[b]{2}{*}{$M$} & \multirow[b]{2}{*}{$S D$} & \multirow[b]{2}{*}{$n$} & \multicolumn{2}{|c|}{$\begin{array}{c}\text { Comparison to Mother } \\
\text { Appraisal Down }\end{array}$} \\
\hline & & & & & $p$ & $d$ \\
\hline \multicolumn{7}{|c|}{ Memory Measures: } \\
\hline Grade 1 & Mother Appraisal Down & 4.55 & 1.59 & 72 & - & - \\
\hline \multirow[t]{3}{*}{ (ages 6-7) } & Null & 4.76 & 1.36 & 75 & .319 & .145 \\
\hline & Teacher Appraisal Down & 5.01 & 1.26 & 75 & .032 & .322 \\
\hline & Mother Appraisal Up & 5.20 & 0.91 & 74 & .003 & .503 \\
\hline \multirow{4}{*}{$\begin{array}{l}\text { Grade } 6 \\
\text { (ages 11-12 }\end{array}$} & Mother Appraisal Down & 3.92 & 1.63 & 72 & 一 & - \\
\hline & ) Null & 4.25 & 1.43 & 75 & .174 & .213 \\
\hline & Teacher Appraisal Down & 4.24 & 1.46 & 75 & .181 & .207 \\
\hline & Mother Appraisal Up & 4.52 & 1.25 & 74 & .013 & .413 \\
\hline \multirow{4}{*}{$\begin{array}{l}\text { Grade } 9 \\
\text { (ages 14-15 }\end{array}$} & Mother Appraisal Down & 3.49 & 1.87 & 72 & - & - \\
\hline & ) Null & 3.69 & 1.62 & 75 & .482 & .111 \\
\hline & Teacher Appraisal Down & 3.75 & 1.75 & 75 & .355 & .141 \\
\hline & Mother Appraisal Up & 4.09 & 1.40 & 74 & .031 & .362 \\
\hline \multicolumn{7}{|c|}{ Current Feelings Measure: } \\
\hline \multirow[t]{4}{*}{ Current } & Mother Appraisal Down & 3.96 & 2.16 & 72 & - & - \\
\hline & Null & 4.50 & 1.52 & 75 & .046 & .292 \\
\hline & Teacher Appraisal Down & 4.74 & 1.64 & 75 & .004 & .409 \\
\hline & Mother Appraisal Up & 5.12 & 1.15 & 74 & .000 & .675 \\
\hline
\end{tabular}

Note. The $p$ values given here are for independent $t$-test group comparisons to the Mother Appraisal Down condition, with memory of love towards mother at that specified time period as the dependent measure. 


\section{Appendix S1 \\ Experimental Groups: \\ Randomly Assigned Appraisal Condition Writing Prompts}

\section{Mother Appraisal Up Condition}

Please write 3-4 sentences giving the most recent examples of when your mother showed warmth towards you.

Please write 3-4 sentences giving the most recent examples of when your mother showed competence (effectiveness) in her life.

Please write 3-4 sentences giving the most recent examples of when your mother showed generosity towards you.

Please write 3-4 sentences giving the most recent examples of when your mother offered good guidance towards you.

Please write 3-4 sentences giving the most recent examples of when your mother gave and received love from you.

\section{Mother Appraisal Down Condition}

Please write 3-4 sentences giving the most recent examples of when your mother showed a lack of warmth towards you.

Please write 3-4 sentences giving the most recent examples of when your mother showed a lack of competence (effectiveness) in her life.

Please write 3-4 sentences giving the most recent examples of when your mother showed a lack of generosity towards you.

Please write 3-4 sentences giving the most recent examples of when your mother gave you bad guidance.

Please write 3-4 sentences giving the most recent examples of when your mother did not give love to you.

\section{Comparison Groups:}

Teacher Appraisal Up (Pilot) and Teacher Appraisal Down (Study 2) Conditions

The same wordings were used as the corresponding mother conditions (shown above), except substituting the words "your mother" with "a teacher."

\section{Null Condition}

Participants received no writing prompts and proceeded to the next part of the study.

Note. For the writing prompt a minimum number of 50 characters was required to be entered for each prompt before the participants could proceed to the next page. 


\section{Appendix S2}

\section{Current Appraisal of Mothers Questions}

How do you evaluate your mother currently on:

[Appraisal of attributes of the mother (attributes relevant to or important in parenting): composite score $=5$ item mean]

1. Current emotional warmth of your mother:
o Poor
o Fair [coded 1]
o Good [coded 2]
o Very Good [coded 4]
o Excellent [coded 5]
o Not applicable [coded as missing data]

2. Current competence (effectiveness) in life of your mother:

3. Current generosity of your mother:

4. Quality of current parenting in terms of good guidance from your mother:

5. Quality of current parenting in terms of giving and receiving love from your mother: 


\section{Appendix S3}

Memory of Love towards Parents Questionnaire (MLPQ; 10-item version (example subscale $=$ Grade 1).

\section{First Year of Elementary School}

Remember back to how you felt about your mother during the year in which you were in first grade (how you felt toward her at that time).

First grade is typically experienced at ages 6-7 years in the United States, and is the first year of Elementary School.

$1^{*}$. During the whole year when you were in first grade, how often on average did you feel love toward your mother?

I Never Knew This Parent At All Never 0 $\bigcirc$
2

1
3

$\bigcirc$
All the

5

$2^{*}$. During the whole year when you were in first grade, how strong on average was your love toward your mother?

I Never Knew

This Parent At Nonexistent All

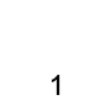

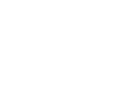

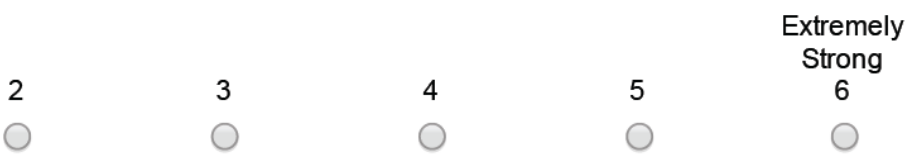

$3^{*}$. During the whole year when you were in first grade, how often on average did you feel affection toward your mother?

$4^{*}$. During the whole year when you were in first grade, how strong on average was your affection toward your mother?

5. During the whole year when you were in first grade, how often on average did you feel warmth toward your mother?

6. During the whole year when you were in first grade, how strong on average was your warmth toward your mother?

7. During the whole year when you were in first grade, how often on average did you feel fondness toward your mother?

8. During the whole year when you were in first grade, how strong on average was your fondness toward your mother?

9. During the whole year when you were in first grade, how often on average did you feel caring toward your mother?

10. During the whole year when you were in first grade, how strong on average was your caring toward your mother?

[Notes. The Likert-type scale for question 1 was used on subsequent odd numbered questions, and question 2's on subsequent even numbered questions. In other subscales (Grade 6, 9, and Current) changed the words "first grade." An example item of the Current subscale is: "Currently how often do you feel love toward your mother?" The anchor "I never knew this parent at all" is coded as missing data. *The 4-items used in Study 3.] 